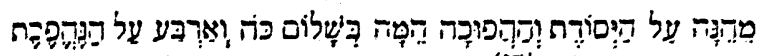
10

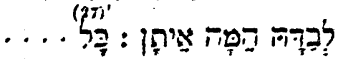

Grundlage (folgen) und ungewendet (vor derselben), diese sind כשלום כה; vier aber kummen nur umgewendet, diese sind ('). [27] Alle ...

A. Harkavy.

\title{
Ueber die Genesis des Judenthums.
}

Von Rudolf Smend.

. I.

Israel und das Judenthum, Israeliten und Juden sind für die populäre Vorstellung ziemlich identische Begriffe, in Wahrheit sind sie sehr verschieden. Das alte Israel war ein Volk und ein nationaler Staat, das Judenthum eine religiöse. Gemeinde. Hier haben wir die in der Weltgeschichte völlig vereinzelt dastehende Thatsache, dafs die nationale Religion den Untergang des nationalen Staates überdauerte und den Rest des alten Volkes sogar viel fester zusammenschlofs áls einst Staat und Volksthum es ver-

V.26. L. כה בה st. (wohl Druckfehler).

1) S. Donasch; 'Kritik (p. 2-3, Nr. 6), wo diese Eintheilung S.'s citirt wird. H. In S.'s Commentar zum Exodus (cap. 26) heifst es ebenfalls, dafs die eilf Buchstaben אברו יבל מפ'שת den Wörtern am

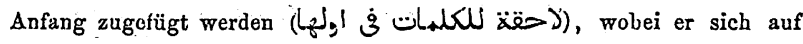
seine Poetik beruft (كلا قل شترحنا·ف كتاب الشعر); s. die ron mir im 1877 p. 287 veröffentlichte Stelle); wahrscheinlich ist der iאג, der als. Anleitung zur Poesie zu dienen bestimmt war, gemeint, wie auch Ka ufmann (Hebr. Bibliogr. 1878, p. 68) vermuthete. 
mocht hatten. Diese merkwürdige Metamorphose war freilich nur deshalb möglich, weil die Religion schon im alten Israel 'gegenüber von Staat und Volksthum eine solche Selbständigkeit erlangt hatte, dals sie nicht in den Untergang jener verwickelt wurde, - und mehr als das, die Religion hatte den Untergang von Staat und Volksthum längst gefordert, ehe er eintrat. Trotżdem wäre es ein Irrthum, zu glauben, dals die israelitische Religion von jeher abgesehen von Staat und Volksthum diese Selbständigkeit besessen oder gar in dieser Weise ihnen gegenübergestanden hätte. Was das Facit der Geschichte des alten Israel war, kann nicht ihr Ausgangspunkt gewesen sein.

Die Theokratie war im alten Israel eine andere als im Judenthum. Von Jahves Macht und dem letzten Ziel seines Waltens dachte man beide Male wesentlich dasselbe, die Nöthigung, sich seinem Willen zu fügen, wurde hier nicht weniger lebhaft empfunden als dort, auch der Inhalt des göttlichen Willens an sein Volk wurde nicht wesentlich verschieden vorgestellt, obwohl natürlich auf allen diesen Punkten in Laufe eines Jahrtausends vielseitige Fortschritte zu verzeichnen sind. Die Hauptsache war vielmehr die, dafs hier ein jugendlich kräftiges und gesundes Volk sich mit seinem Gott in wesentlicher Uebereinstimmung und von ihm getragen wufste, dort dagegen die Trümmer des entarteten und in seiner Entartung untergegangenen, an seiner ganzen Natur irre geworden waren und unter dem Eindruck der furchtbaren Schläge, die es getroffen hatten, den schwersten Druck des göttlichen Zorns und den schärfsten Contrast zwischen den göttlichen Anforderungen und Israels Leben und Wesen empfanden. Das alte Israel hatte den Willen Jahves in seinen Priestern und Propheten $d$. h. aber in sich selbst lebendig getragen, jetzt stand er ubjectiv in dem h. Gesetzbuch dem Volke gegenüber - die Form des göttlichen Willens war eine wesentlich andere. I)a 
liefs der Eifer, der durch dic Erfüllung des Gesetzes die göttliche Gnade wicdergewinnen wollte, neben dem supranaturalen Gesetzbuch, das nun für alle Verhältnisse des Lebens die alleinigre Richtschnur wurde, keinen Platz mehr für das natürliche Volksleben, und so auch nicht für seine iufsere Form, den politiscben Staat und das Künigthum. In der That sind aber auch alle anderweitigen Unterschiede zwischen Israel und dem Judenthum auf jenen einen Gegensatz zurückzuführen : der Untergarg des israelitischen Staates und Volksthums ist die wichtigste Epoche der vorchristlichen Offenbarungsgeschichte.

Auch die biblische Wissenschaft hat erst in neuester Zeit zwischen dem alten Israel und dem späteren Judenthum unterscheiden gelernt und so erst eine lebendige Vorstellung von der alttestamentlichen Religionsgeschichte gewonnen. In der That ist das eine die Vorbedingung des andern. Ohne jene Unterscheidung ist man ohne Antwort auf die Frage, was doch die tragische Geschichte.Israels bedeutet habe, was denn die Resultante des gewaltigen Kräftespiels war, das auf den Berg Zion wirkte, wozu überhaupt der grofse weltgeschichtliche Apparat gegen Israel und für Israel in Bewegung gesetzt wurde. Antwortet man, die Prophetie sei dadurch ins Leben gerufen, so ist zu erwidern, dals die prophetische Predigt der Hauptsache nach aus selbstverständlichen Gedanken besteht, wenn das (Gesetzbuch älter ist als die Prophetie ${ }^{1}$ ). Auch die messianische Hoffnung ist $\mathrm{m}$. E. ein nothrendiges Complement des Gesetzbuchs. In Wahrheit setzt man für gewöhnlich aufser Augen, was die Prophetie innerhalb der altt. Geschichte bedeutet hat. Man hält sich meistens allzu einseitig an diejenigen prophetischen Gedanken, die über

1) Befremdlich ist der immer wiederkehrende Hinweis auf den neutestamentlichen Ausdruck „Gesetz und Propheten“, als ob der etras anderes bedeutete als der erste Theil des Kanons und der zweite. 
das Niveau des übrigen A. T. hinausgehen, und setzt sie in Parallele zum N. T. Aber der Werth dieser prophetischen Gedanken kann doch nur darin bestehen, dafs sie nicht nur innerhalb einer Geschichte entstanden sind, sondern auch in einer Geschichte fortgewirkt haben. Man kann getrost behaupten, dafs die Propheten als die (wenn auch nur indirecten) Begründer des Judenthums wichtiger sind denn als die Weissager vom N. T. Was sie über das Judenthum hinaus haben, ist uns nur werthvoll zur Verbürgung dessen, was im Judenthum verborgen ist. Theologisch (im engeren Sinne) pflegt man sich für das Judenthum kaum zu interessiren. Man hat es allerdings zu einem grofsen Theil in dem, was man gewöhnlich Mosaismụs nennt. In Sonderheit wird der Zeitraum zwischen dem letzten Buch des altt. Kanons und dem N. T. gemeinhin als ein Vacuum angesehen, das wesentlich nur von arçhäologischem Werthe sei, die innere Geschichte des vorchristlichen Judenthums wird in der That fast ausschliefslich von diesem Gesichtspunkte aus betrachtet, als Basis für das Verständnifs des N. T. dient die neutl. Zeitgeschichte anstatt einer Geschichte des Judenthums. Es kann aber keinem Zweifel unterliegen, dafs die nächste Aufgabe der altt. Theologie vor allen Dingen die Geschichte des vorchristlichen Judenthums ist.

Freilich stellt die Ueberlieferung das Gesetzbuch an den Anfang der israelitischen Geschichte, und für das spätere Judenthum war der Gedanke einer geschichtlichen Entwickelung seines Glaubens und seiner Sitte ebenso unfalsbar wie für die katholische Kirche. Dem steht aber zunächst die Thatsache gegenüber, dafs der Pentateuch und namentlich das Gesetz des Pentateuchs keine einheitliche Gröfse, sondern aus mehreren und zwar sehr verschiedenartigen Gesetzbüchern zusammengestellt ist. Der Dekalog von Ex. 20, der von Ex. 34, das Bundesbuch Ex. 21-23, das Deuteronomium, das in Lev. 17-26 zu Grunde liegende Corpus,

Zeitscbrift f. d. alttest. Wiss. Jalurgung 2, 1882. 
allo diese Stlicko sind von einander und von dem Rest der pentateuchischen Gesetze, die man neuerdings meistens unter dem Namen des Priestercodex zusammenfalst, cha rakteristisch verschieden. In der That hat jede dieser Gruppen ihren eigenthümlichen Typus und zwar in solchem Grade, dafs man fragen muls, welche von ihnen denn vorzüglich als „das Gesetz" zu gelten habe. Nun ist der Pentateuch allerdings in seiner Gesammtheit die Magna Charta der jüdischen Theokratie gewesen, aber zu diesem seinem Charakter haben die verschiedenen Gruppen seiner Gesetze in sehr verschiedenem Grade beigetragen. Am wenigsten der fast ausschliefslich moralische Dekalog von Ex. 20 und das Bundesbuch, das von religiös-humanem Standpunkt aus vor allem die privatrechtlichen Verhältnisse eines Bauernvolkes behandelt. Das vornehmste und grölste Gebot war es nicht, was die jüdische Gemeinde zusammenhielt und worauf zunächst der eigenthümlich gesetzliche Charakter ihrer Religiösität beruhte, das waren vielmehr die Cultus- und Ceremonialgesetze des Pentateuch d. h. der sogenannte Priestercodex mit dem davon unabtrennbaren Corpus Lev. 17-26. Was die verschiedenen Gruppen der pentateuchischen Gesetze der Hauptsache nach von einander unterscheidet, ist der verschiedene Grad, in dem sie den Cultus und die religiöse Sitte fixiren und zwar im Gegensatz gegen den volksthümlichen Brauch. Jenes Moment findet sich schon Ex. 20-23. 34, in höherem Grade im Deuteronomium, mehr noch Lev. 17-26, den Priestercodex füllt es vollständig aus ${ }^{1}$ ). Auch der pole-

1) Der Dekalog von Ex. 34 ist freilich ausschlie/slich ritual, wie im Priestercodex erscheinen auch hier Gottesdienst und religiöse Sitte als die Hauptsache in der Religion. In gewissem Sinne hat der Gegensatz zwischen dem Bundesbuch und dem Priestercodex in der That im alten Israel bestanden, das . wissen wir nicht nur aus dem Nebeneinander dieser beiden-Dekaloge, sondern vor allen Dingen aus dem Gegensatz 
mische Gegensatz gegen das volksthümliche Wesen ist an einzelnen Pupkten schon Ex. 20-23. 34 deutlich, seinen Höhepunkt erreicht er im Deuteronomium und Lev. 17-26, im Priestercodex ist weniger davon zu spüren, das gesetzliche System von Cultus und Sitte wird hier zumeist ohne Rücksicht auf eine im Volksthum entgegenstehende Wirklichkeit entwickelt, nicht im Gegensatz dazu, aber auch nicht im Anschlufs daran. Hier gilt der Gottesdienst Israels als etwas durchaus Geoffenbartes. Somit steht doch der Priestercodex dem Volksthum am fernsten. Man kann sonach sagen, dals die verschiedenen Gesetzesgruppen in verschiedenem Grade „Gesetz " sind, am meisten der Priestercodex und Lev. 17-26, am wenigsten das Bundesbuch. Zwischen beiden steht das Deuteronomium, das nach beiden Seiten verwandtschaftliche Beziehungen hat. Die Frage nach dem Alter des pentateuchischen Gesetzes kommt also wesentlich auf die nähere nach dem Alter des Priestercodex hinaus. Von der Beantwortung dieser Frage hängt es ab, welche Vorstellung wir uns vom alten Israel zu machen haben.

Als ein Kirchen- und Priesterstaat erscheint Israel nach dem Priestercodex. Ein Heer von Klerikern, das durch eine exorbitante Abgabenlast unterhalten werden mufs, bildet den Kern des Volkes - das ist der Stamm Levi. Aber auch dieser ist wieder scharf in sich gegliedert, in gemeine Leviten und vornehme Priester, die wiederum

der Propheten zum Volke. Es ist eben wesentlich die volksthümliche Anschauung, die Ex. 34 zum Worte kommt, obwohl auch ein gewisser Gegensatz zum Volksthum aus einzelnen Sätzen deutlich ist; vgl. sonst Gen. 28, 20 ff. Der. fundamentale Unterschied dieser Sätze, die grofsentheils im Bundesbuch wiederkehren, vom Priestercodex ist übrigens deutlich genug. Der Cultus ist eine selbstrerständliche Sache und mit zebn Worten ist alles gesagt. Der Dekalog von Ex. 20 scheint im Gegensatz zu dem von Ex. 34 entstanden zu sein, das Umgekehrte ist wenigstens schwer denkbar. 
im Hohenpriester gipfeln. Der trägt den Purpur und das Diadem, der heifst nder Gesalbte", von seinem Tode datirt jedesmal eine neue Acra. Von der bürgerlichen Obrigkeit ist so zu sagen nicht die Rede. Die Stammesfürsten kommen lediglich als Spender von Opfern und Weihgeschenken in Betracht. Im Zusammenhang der hexateuchischen Frzählung wird freilich von Josua neben Eleasar Notiz genommen, aber nach Num. 27 ist nicht Josua der Führer Israels, sondern Eleasar regiert und Josua hat nur den Ausspruch von Urim und Thummim zu executiren. In Wabrheit scheint im gesetzlichen Gottesdienst, der Israel überhaupt geoffenbart ist, das ganze Leben des Volkes aufzugehen. Opfer und Ceremonien erscheinen als seine einzige Lebensäufserung, die bis ins Kleinste und Geringste vom göttlichen Gesetze bestimmt ist. In einem Kalender bestimmt Gott seine zahlreichen Feste, die ein systematisch gegliedertes Ganzes bilden und in dem einen Moment ihren Höhepunkt haben, wo der Hohepriester am Versöhnungstage das Allerheiligste betritt. In einer detaillirten Tabelle verordnet Gott auf das genaueste das Wie und Was des Gottesdienstes für jeden Tag des Jahres, und für jede Lage des Liebens ist eine bestimmte religiöse Observanz durch Gottes Gebot vorgeschrieben. So ist das ganze Leben des Volkes, des Einzelnen wie der gesammten Gemeinde von einem Netze gottesdienstlicher Handlungen überzogen, die auf Schritt und Tritt an den Gott Israels und sein Gesetz erinnern, ja das ganze Leben des Volkes ist gleichsam ein 'grofser ununterbrochener sacramentaler Gottesdienst, der sich um die Stiftshütte dreht. Nur diesen Sinn hat jene Lagerordnung, welche die 12 Stämme concentrisch um die Stiftshütte und den Stamm Levi gruppirt. Das ist das Joch des Gesetzes, das nach hergebrachter Meinung schon Mose dem halsstarrigen Volke aufgelegt hat, der harte Zuchtmeister, durch den Israel von jeher erzogen wuide. 
Es scheint auf den ersten Blick befremdlich, dals diese Gruppe von Gesetzen recht eigentlich das „Gesetz" Israels ausgemacht haben soll, da in ihr doch gerade das am wenigsten zum Ausdruck kommt, was wir als den wesentlichsten Unterschied der alttl. Religion von den heidnischen zu betrachten gewohnt sind. Sollte diese Cultusgesetzgebung wirklich die gesammte religiöse Sphäre ausfüllen? Oder haben wir den viel bescheideneren Versuch vor uns, nur die gottesdienstliche Seite der Religion darzustellen? So stellt man wohl die Alternative, aber mit Unrecht. Wenn der Priestercodex fast ausschliefslich Cultusgesetze enthält, so folgt darans allerdings, dafs seine Verfasser gerade die Aufsenseite der Religion als das Wichtigste in der mosaischen Offenbarung betrachteten. Dafs ihnen die Religion überhaupt hierin aufging, ist damit nicht gesagt. Aber einen anderen Sinn als den bezeichneten kann diese Gesetzgebung in dem grofsartigen Rahmen der Urgeschichte von der Schöpfung der Welt bis zur Einnahme Kanaans durch Israel doch nicht haben.

In der That liegt die pädagogische Tendenz dieses Gesetzes auf der Hand, so energisch wie hier ist wohl sonst nie in der Weltgeschichte der Versuch unternommen, ein ganzes Volk religiös zu erziehen. Deutlich ist aber auch, dafs der oder die Urheber dieses Gesetzes von der natürlichen Verderbtheit Israels aufs tiefste durchdrungen waren, und es fragt sich doch sehr, ob wir eine solche Erkenntnifs bei dem voraussetzen dürfen, der eben erst dies Volk geschaffen hatte, ob ein eben entstehendes Volk für einen solchen Gedanken auch nur das geringste Verständnifs haben konnte, geschweige denn soviel, dal's es dies Joch auf sich nahm. Vatke hat ferner darauf aufmerksam gemacht, dafs der Priestercodex förmlich den Begriff einer Kirche entwickelt, dieser aber erst als die Nachbildung eines Staates begreiflich ist, wozu Israel es erst im Laufe seiner Geschichte brachte. Wirklich er- 
scheint auch die römische Kirche als undenkbar ohne den vorhergehenden altrömischen Staat.

Nun haben solche Erwägungen freilich keine Bedeutung für diejenigen, die das Wesen der gijttlichen Offenbarung wesentlich im Gegensatz zur Natur suchen und die deshalb das Volk der Offenbarungr möglichst abnorm vorzustellen gewohnt sind. Indessen sind wir über die Geschichte des alten Israel genügend unterrichtet, um auf Grund der uns zu Gebote stehenden Quellen zunächst wenigstens die Gültigkeit des Priestercodex für die vorexilische Zeit leugnen zu müssen. Was die mosaische Zeit angeht, so braucht heutzutage kaum noch bewiesen zu werden, dafs die Theokratie des Priestercodex in der Wüste nicht existirt haben kann. Es genügt an Am. 5, 25 oder an die anderweitige, leider verstümmelte Beschreibung des mosaischen Heiligthums Ex. 33 zu erinnern, wo das Zelt aufserhalb des Lagers steht, und Mose und der Knabe Josua die Stelle Aharons, seiner Söhne und der 22,000 Leviten vertreten. Fast allgemein wird die erzählende Form des Gesetzbuchs eben nur für eine Form genommen, in die Spätere ihren Glauben an die mosaische Herkunft oder auch nur den Gültigkeitsanspruch der einzelnen Gesetze einkleideten. Somit kann der Priestercodex nicht selbst für sein Alter und seine Geltung in der mosaischen Zeit zeugen.

Aus Neh. 8-10 wissen wir, dals sogar die nachexilische Gemeinde fast ein Jahrhundert lang bestanden hatte, bevor ihr der Priestercodex bekannt und feierlich eingeführt wurde. Nach einer durchaus glaubwürdigen Ueberlieferung hatte der Schriftgelehrte Esra ihn aus Babylonien mitgebracht. Ein anderer Theil des Pentateuchs, das Deuteronomium, war dagegen schon einige Jahrzehnte vor der Zerstörung Jerusalems bekannt und zum öffentlich gültigen Gesetzbuch erhoben worden (2 Kön. 22. 23). Betreffs des Deuteronomiums wird nun ziemlich allgemein 
angenommen, dals es kurz vor seiner Auffindung entstanden war. Die Forderungen dieses Gesetzbuchs passen in der That allein auf die Zeit Josias. Dasselbe gilt aber in noch viel höherem Grade vom Priestercodex betreffs der exilischen und nachexilischen Zeit und man hat gar keinen Grund hier eine Folgerung abzulehnen, die man dort acceptirt ${ }^{1}$ ). Wie vor der Zeit Josias keine Spur vom Deuteronomium und überhaupt von keinem öffentlich gültigen Gesetzbuch in der israelitischen Geschichte zu entdecken ist, so wenig findet sich vor Esra eine Spur vom Priestercodex. Was diese Thatsache $\mathrm{zu}$ bedeuten hat, folgt aber daraus, dals umgekehrt in der Zeit nach Josia das Deuteronomium sich in Literatur und Leben sehr bemerkbar macht, wenn auch nicht in dem Malse wie seit Esra der Priestercodex.

Nach der Chronik sollte man freilich meinen, der Priestercodex sei von jeher der Angelpunkt gewesen, um den sich das Leben Israels bewegte. Aber dies nach Alexander dem Grofsen geschriebene Buch kann neben der parallelen Ueberlieferung der Bücher Samuelis und Könige nicht in Betracht kommen. Denn was die Entstehung jenes Buches wesentlich veranlafst hat, ist der Umstand, dals jene älteren Geschichtsbücher von dem Priestercodex nichts wissen. Sie geben uns ein Bild vom alten Israel, welches Zug um Zug seinen Forderungen aufs gröblichste widerspricht, und so wenig sie mit den Zuständen des alten Volkes zufrieden sind und so scharf sie dasselbe kritisiren, so ist der Malsstab, den sie dabei anlegen, doch offenbar ein ganz anderer als der des Priestercodex. Der Verfasser

1) Es kann hier nicht der Ort sein, den von Anderen geführten Beweis dieser Behauptung zu recapituliren. Nur auf eine Kleinigkeit möchte ich aufmerksam machen. In der trockenen Erzählung des Priestercodex über die Erzväterzeit findet sich auf menschlicher Seite nirgendwo ein Motiv zu handeln, die ganze Geschichte läuft völlig automatisch ab. Dio einzige Ausnahme bildet der $\cdot$ Schmerz Isaaks und Rebekkas über die eanaanitischen Ehen Esaus (Gen. 28 vgl. Num. 25). 
der Chronik wollte diesem Mangel abhelfen, den er ohne 'Wweifel fur einen nur scheinbaren hielt. Dic mosaische Abfassung 'des Pentateuchs und seine beständige Gültigkeit war für ihn selbstverständlich und so meinte er, die ältere Ucberlieferung nur richtig zu interpretiren, indem er sie überall nach dem Gesetzbuch und ïberhaupt nach den Zuständen und Vorstellungren seiner Zeit corrigrirte und umarbeitete. Das lisrael der Chronik ist eine alterthümliche Verkleidung der jüdischen Gemeinde, daher diese Bilder voll innerer Contraste und Widersprüche, die hin und wieder fast ans Groteske streifen, die aber gleichwohl sehr lehrreich sind, sofern sie zeigen, wohin die $\mathrm{Zu}$ rücktragung des Gesetzes in die vorexilische Zeit führt. Im engsten Zusammenhang damit steht ein stark ausgeprägter religiöser oder vielmehr dogmatischer Pragmatismus der Darstellung, wonach Unglück überall Strafe für eine bestimmte Sünde und zwär für Ungehorsam gegen bestimmte Gebote des Gresetzes und umgekehrt Glück als Lohn für gesetzliche Frömmigkeit erscheint. Diesen Causalnexus bemüht sich der Verf. auf allen Punkten aufzuzeigen, indem er Ursache und Wirkung auch da überall concret ausmalt, wo die ältere Ueberlieferung uns darüber völlig im Dunkeln lälst, - Frömmigkeit und Gottlosigkeit nach dem Priestercodex, Glück und Unglück nach oft sehr willkürlichen Combinationen. In sehr vielen Fällen wird sogar von Ursache auf Wirkung und umgekehrt lediglich geschlossen, das rein vermuthete Glied der Kette darum aber nicht weniger concret geschildert wie das überlieferte.

Die älteren Geschichtsbücher, Richter, Samuelis und Könige, haben ihre vorliegende Gestalt wesentlich im Exil erhalten. Diese letzte (so zu nennende) Bearbeitung ist das Werk mehrerer Hände und muls übrigens wegen ihrer Verwandtschaft mit den Propheten Jeremia und Ezechiel für einen getreuen Ausdruck der damaligen Denkweise gelten. Sie steht auf dem Standpunkt des Deuteronomiums. 
Was sie aber aufserdem vom Chronisten unterscheidet, ist einmal der Umstand, dafs jener Pragmatismus von ihr bei weitem nicht in demselben Malse entwickelt wird und dann, dafs sie dio Vergangenheit viel weniger idealisirt, als vielmehr verdammt. Es liegt hier nicht nur ein anderes Gesetzbuch zu Grunde, sondern auch die gesammte Anschaunng ist eine vicl weniger gesetzliche. Denn der Glaube an das mosaische Gesetzbuch hat zur nothwendigen Consequenz die Meinung, dafs es seit Mose in Israel regiert oder doch wenigstens seinen Anspruch auf Anerkennung immer wieder geltend gemacht babe. So stellt denn auch der Chronist die Sache dar. Dagegen ist das Gesetz zunïchst im bewufsten Gegensatz gegen die Vergangenheit entstanden. Es sollte anders werden. Der letzte Verfasser des Konigsbuchs giebt zu, dals gerade diejenige Forderung des Douteronomiums, auf die er das meiste Gewicht legt, nümlich das Verbot der Hohen, erst von Iliskia oder vielmehr von Josia durchgefuhrt sei, ja melir als das, nach seiner Moinung (die in Wahrheit auch die des Deuteronomiuns ist) hat jene Forderung erst seit dem salomonischen Tempelbau Gultigkeit gehabt. Von dem Zeitpunkt ab wird der Hohendienst beanstandet und allen KUnigen bis auf Hiskia und Josia zum Vorwurf gemacht, fur die kiltere Zeit wird er gerechtfertigt (1 Kon. 3,.2) und passirt deshalb in den Buchern der Richter und Samuelis ungerugt. Freilich liffst or seit Salomo von Zeit zu Zoit Propheten auftreten, die die Hauptgebote des Deuteronomiums geltend machon, aber das hat hier doch noch einen anderen Sinn als in der Chronik. Ueberhaupt geht der Begriff der Thora fur den Verfasser durchaus nicht im Gesetzbuch auf (2 Kon. 17, 13 vorgl. Esra 9, 11).

Andererseits wird fast die gesammte Vergangenheit aufs entschicdenste. verurtheilt. Es soll gezeigt werden, dafs das Volk von jeher einen unaustilgbaren Haug zur Gottlosigkeit in sich trug und schon in der Zoit seiner 
Entstehung seine grundverderbte Natur an den Tag leste. Schon nach den Erfahrungen der Richterzeit konnte man - Uber den Aus'ang der Geschichte Israels nicht zweifelhaft sein, ja sogar dic Zeit des Wüstenzugres, die von den ilteren Propheten und selbst noch von Jeremia so granz anders beurtheilt wird, erscheint in diesem Lichte. Später nach Salomos Tode fiel der gröfste Theil des Volkes für immer von seinem Gott ab, bei der Entstehung des Reiches Ephraim war auch schon sein Untergang besiegelt. Auch das Reich Juda war im Grunde nicht viel besser. Obwohl manche seiner Könige fromm waren, so kamen doch nur Hiskia und Josia dem David gleich, und deren Frömmigkeit konnte die Gottlosigkeit nicht abstellen, die nun einmal zu tief in der Natur des Volkes stak. Darum mufste auch Jerusalem mit dem Tempel fallen, wie schon dem Salomo für den Fall des.Götzendienstes, ja schon den Vätern, die in Kanaan einzogen, durch Mose angedroht war. Gott wohlgefällig und fromm war in alter Zeit das Geschlecht, das unter Josua das heilige Land eroberte, fromm war Israel während der Regierungszeiten der Richter, fromm war David, an dessen Namen sich die Erinnerung an die einstige Macht und Grölse Israels knüpfte, Salomo, der Besitzer einer Herrlichkeit, die den Späteren märchenhaft erschien, und vor allen Dingen der Erbauer des Tempels,war es wenigstens in seiner Jugend. Dafs diese Auffassung der israelitischen Geschichte von einem sehr unvollkommenen Vergeltungsglauben beherrscht ist, ist deutlich und nicht minder deutlich die Zeit, in der sie sich bildete. Die furchtbare Thatsache, dafs Jahve sein eigenes Volk vernichtet hatte, forderte ihre Erklärung aus einer ungeheueren Schuld, die auf Israel lastete. Ein gottloses Geschlecht war es, das der vernichtende Schlag traf, und seine Gottlosigkeit manifestirte sich am deutlichsten in dem Götzendienst, um den sich der Kampf zwischen Volk und Prophetie zuletzt eigentlich gedreht hatte und der übrigens 
zu einem guten Theil wirklich in uralte Zeiten zurückreichte ${ }^{1}$ ). So unvollkommen, einseitig, willkürlich, ja ungerecht diese Beurtheilung der Vergangenheit deshalb auch im Einzelnen ist, es ist nicht aus der Luft gegriffen, wenn der ganzen Vergangenheit und namentlich auch schon der Richterzeit Götzendienst vorgeworfen wird. $\mathrm{Ja}$ es ist in dieser Geschichtsbetrachtung ein grolser Fortschritt zu constatiren. Sie verdient schon deshalb alle Anerkennung, weil sie mit dem Vergeltungsglauben entschiedenen Ernst macht. Man schob ja nicht die Schuld von sich ab, sondern man klagte sich selbst an, indem man die Väter anklagte, man bekannte die eigene Schuld, indem man die ganze Vergangenheit als eine grofse Schuldenlast hinstellte (Neh. 9). Wichtiger ist ein Anderes. Das Wesen der Sünde scheint etwas oberflächlich aufgefafst zu werden, wenn sie hier wesentlich nur als Götzendienst erscheint, aber andererseits ist dasselbe hier doch viel tiefer erfalst, als früher. Im Anschlufs an Jeremia wird die Sünde hier als ein unausrottbarer Hang der gottwidrigen Natur Israels begriffen. Bei den älteren Propheten (Hosea macht aus bekanntem Grunde einigermafsen eine Ausnahme) ist die Sünde dagegen eine ziemlich unbegreifliche Entartung der ursprünglich guten Natur des Volkes. Ebenso bezeichnet die Energie, mit der eine fortgehende Vergeltung postulirt

1) Die Meinung des Deuteronomiums, Ezechiels und des Corpus Lev. 17 ff., dafs der volksthümliche Gottesdienst grofsentheils kanaanitischer Götzendienst sei, den Israel bei seiner Einwanderung angenommen habe, ist, wie Wellhausen bemerkt, nicht unbegründet. Sie wird durch die ältere Ueberlieferung (Num. 25. Hos. 9) und nicht minder durch die Sagen der Genesis bestätigt. Obendrein ist das Problem des israelitischen Götzendienstes oder vielmehr des frühzeitigen Kampfes gegen denselben ohne eine derartige Annahme unlösbar, im Gegentheil ist es undenkbar, wie eine solche Vermischung hätte vermieden werden können, als ein Hirtenvolk in die höhere Cultur eines ackerbauenden eintrat. 
und constatirt wird, einen Fortschritt liber die altere Zeit hinaus. Die Mängel dieser Geschichtsauffassung liegen auf der Hand, aber es ist leichțer, dieselben zu rügen als sie zu verbessern. Es ist eben schwer, wenn nicht unmöglich, den Fortschritt des göttlichen Gerichts in der Geschichte aufzuzeigen.

Auf diesen beiden Punkten n̈̈hert sich diese deuteronomistische Religionsauffassung freilich dem Gesetz, aber den eigentlich gesetzlichen Standpunkt erreicht sie bei Weitem noch nicht. Ihre Gesetzlichkeit geht wesentlich auf in der Perhorrescirung der grob heidnischen Elemente, die dem volksthümlichen Grottesdienst von altersher noch anklebten oder von aufsen in ihn eingedrungen waren. Der verwilderte Baum wird mit Axt und Säge zugestutzt, das Deuteronomium sucht ihn überdies durch Einmischung humaner Elemente zu veredeln, aber im Uebrigen läfst man ihn wie einen natürlichen Baum wachsen. Man nimmt grofses Interesse am Tempel, am Cultus aber wesentlich nur ein negatives. Jahve soll nicht in falscher Weise verehrt werden, positiv wird darauf kein Nachdruck gelegt, man denkt noch nicht daran; dals der Cultus auf göttlicher Offenbarung beruhe. Der Prophet Jeremia stellt es als eine notorische Thatsache hin, dals Jahve beim Auszuge aus Aegypten nichts von Opfern geboten habe ( 7,22$)$. Nach der deuteronomistischen Geschichtsschreibung besteht die Frömmigkeit Josuas, Hiskias und Josias nicht sowohl darin, dafs sie den rechten Gottesdienst übten, als dafs sie den falschen heidnischen resp. die Canaaniter ausrotteten. Wenn es weiter vọn jenen beiden Königen im Anschlufs an ihre Cultusreformation heifst, dafs sie ganz so gethan hätten wie ihr Vater David, dagegen von anderen frommen Königen, die gleichwohl die Höhen duldeten, dafs sie nicht ganz wie David gethan hätten, so ist es schwer, diesen Gedanken auszudenken. Denn auf Davids Zeit findet ja das Verbot der Höhen keine Anwendung. Hier zeigt sich 
recht deutlich das Unfertige in den Anschauungen des Verfassers. In den Büchern Samuelis acceptirt er ohne Weiteres die Schilderung der natürlich edelen Persönlichkeit Davids, die die Mit- und Nachwelt begeisterte, er fuihlt sich nicht gedrungen, die Gesetzlichkeit von Davids Frömmigkeit zu constatiren, wenn er ihn auch in seinem Testament den Salomo im Hinweis auf das Gesetzbuch vor dem Götzendienst warnen lärst.

Zuzugeben ist freilich, dals dieser deuteronomistische Standpunkt, wesentlich über das Deuteronomium hinausgehend, ein religiös-kirchlicher ist. Namentlich ist das Königsbuch eigentlich eine Kirchengeschichte, mit dem Richterbuch steht es nicht viel anders. Im Königsbuch sind der Tempel und die Prophetie die hauptsächlichen Gegenstände des Interesses, dessen Kehrseite der Gegensatz gegen den Götzendienst ist. Nach diesen Gesichtspunkten ist der Stoff aus den älteren Quellen ausgewählt, indem dabei hin und wieder ältere Erzählungen in einem Sinne aufgefalst werden, der ihrem ursprünglichen Geiste völlig fremd ist (1 Kön. 20.22; 2 Kön. 9. 10). Von der äufseren politischen Geschichte erfahren wir sehr wenig, meist nur das, was zugleich auf den Tempel und die Prophetie Bezug hat. Nach ihrem Verhalten zu diesen beiden Dingen werden die Könige beurtheilt. Dadurch bekommt der Patriotismus des Verfassers eine eigenthümliche Färbung, ein profanes Nationalbewulstsein ist nirgends zu verspüren. Dennoch weifs el sehr wohl, was der politische Staat und das Königthum für die Sache der Religion bedeutet hat. Seine messianische Hoffnung ist an das Haus Davids geknüpft, ohne dies kann er sich eine Zukunft Israels nicht denken, ob auch nur wenige Könige den Anforderungen der Religion in seinem Sinne entsprochen hatten. Auf dem Boden des Staates war eben die entstehende Kirche entsprungen, die Könige hatten den Tempel gebaut, königliche Diener waren die Priester der vorexilischen Zeit 
(1 Sam. 2, 25), das Königthum hatte dem deuteronomischen Gesetzbuch Geltung verschafft.

Nirgends zeigt sich in der deuteronomistischen Bearbeitung die Vorstellung einer selbständigen Theokratie, wohl aber ist sie in einigen Erzählungen des Richter- und Samuelisbuchs zu erkennen. Danach wäre die selbständige Theokratie sogar ïlter als das Königthum. Die Erzählung Richt. 19-21, deren Inhalt mit ihren Anfangsund Schlufsworten merkwürdig contrastirt, giebt uns ein Bild vom alten Israel, das schon an den Priestercodex erinnert. Da haben wir ein durchaus geistliches Israel vor uns, eine wesentlich kirchliche Gemeinde, die einmüthig und mit furchtbarem Ernst der einen Aufgabe, das heilige Volk Gottes zu sein, nachtrachtet. Auf die Nachricht von einer unerhörten Schandthat, von verruchten Buben in Gibea an dem Weibe eines Leviten verübt, versammelt sich das ganze Violk wie ein Mann, um Gericht zu halten, und als der Stamm Benjamin die Auslieferung der Schuldigen verweigert, wird er von der übrigen Gemeinde nach furchtbaren Kämpfen fast total ausgerottet. Mit dieser Erzählung, die auf allen charakteristischen Punkten in diametralem Widerspruch mit dem übrigen Richterbuch steht, sind einige Stücke im Buche Samuelis artverwandt. 1 Sam. 7. 8. 10, $17 \mathrm{ff} .12$ soll gezeigt werden, wie dies geistliche Israel der vorköniglichen Zeit das heidnisch weltliche der königlichen Zeit wurde. Wenigstens de jure ist Israel hier dasselbe wie dort, de facto erscheint es freilich in einem völlig gegentheiligen Lichte. Die Wandlung. ist unbegreiflich. Durch und durch heidnisch war das Volk von jeher, seit dem Auszug aus Aegypten ist es immer wieder zu den Götzen abgefallen, jetzt kommt seine heidnische Natur vollends zum Durchbruch im Verlangen nach einem Könige. „Wir wollen sein wie alle Heiden sind", das ist die lästerliche Rede, die diese Rotte allen Bitten und Beschwörungen Samuels entgegenstellt, 
und zuletzt mufs Samuel nachgeben, als der souveräne Stellvertreter Jahves giebt er dem Volke seinen König, indem er zugleich den dereinstigen Untergang von König und Volk weissagt. In Wahrheit schlägt diese Erzählung der gesammten vorexilischen Denkweise Israels, soweit sie uns bekannt ist, in Sonderheit der anderweitigen Ueberlieferung über Samuels Verhältnils zum Königthum, geradezu ins Angesicht. Nicht verruchter Eigenwille des Volkes, sondern die bitterste Noth der Knechtschaft hat Israel zum Königthum geführt, nicht das Volk hat von Samuel einen König verlangt, sondern Samuel ist es gewesen, der längst, ehe das Volk an das Königthum dachte, darin die einzige Rettung gesehen und verlangend wach dem Manne nach Jahves Herzen ausgeschaut hat, der den Saul zuerst als solchen erkannt, ihm seinen Beruf geoffenbart, ihm Mittel und Weg zu seinem Ziel gezeigt und ihm endlich unter geschickter Benutzung eines günstigen Augenblicks zur Krone verholfen hat, und umgekehrt: nicht Samuel machte zuletzt den Saul zum Könige, dazu besals er nicht die Macht, sondern das Volk. Und zwar ist das nach dieser Ueberlieferung die einzige eigentliche That Samuels, als der intellectuelle Urheber des Königthums hat er den Anstofs zur Befreiung Israels gegeben, das ihm deshalb sein späteres Leben verdankt. Indessen tritt die oben skizzirte Erzählung auch auf diesem Punkte der übrigen Ueberlieferung entgegen. Sie nimmt die Befreiung Israels von den Philistern, die Grofsthaten Sauls und Davids direct für Samuel in Anspruch. Ehe vom Königthum die Rede war, hat Samuel das vollführt (1 Sam. 7), damit soll der anderweitigen Ueberlieferung der Boden unter den Füfsen weggezogen werden, das Königthum war hiernach vollkommen überflüssig. Es ist das freilich wiederum ein Ausflufs des bekannten Pragmatismus : war die geistliche Herrschaft nach göttlichem Rechte die einzig wahre, dann mufste Israel dabei auch besser oder wenigstens nicht schlechter 
gefaliren sein als bei der weltlichen. Das war logrisch nicht anders denkbar, ob auch die ganze Geschichte dadurch auf den Kopf gestellt wurde.

Bei einem solchen Verhältnils dieser Erzählungen zur ubrigen Ueberlieferung kann von einem Nebeneinanderbestchen der beiden gar keine Rede sein, sie vertragen sich wie Ja und Nein und es ist verlorene Mühe, sie harmonisiren zu wollen. Die Entscheidung über die zu treffende Wahl kaun nicht zweifelbaft sein. Denn in jenen Stücken ist der innere Widerspruch, der grofse Mangel an Lebenswahrheit überall nicht zu verkennen, der eben dadurch entsteht, dals Vorstellungen und Begriffe in das altisraelitische Volksleben zurückgetragen sind, die sich mit einem lebendigen Volksleben überhaupt nicht reimen. Denn hier wird eben der natürlichen Form des Volkslebens, dem nationalen Königthum, für Israel das Existenzrecht abgesprochen und dasselbe für von vornherein unvereinbar mit Israels Bestimmung erklärt. Wellhausen wird mit der Behauptung Recht behalten, dafs eine solche Vorstellung von dem Verhältnifs geistlicher und weltlicher Macht sich erst bilden konnte, als es keinen israelitischen Staat mehr gab ${ }^{1}$ ). Wer innerhalb des nationalen Staatsverbandes lebte, konnte jenes Verhältnifs in dieser Weise nicht auffassen. Bekanntlich betrachten alle vorexilischen Propheten, sogar noch Jeremia und Ezechiel, den nationalen Staat mit dem Könige an der Spitze als die selbstverständliche Form des idealen Israel der Zukunft. Das ist aber um so bemerkenswerther, als der Kampf der Propheten gegen die Excesse des Königthums fast ebenso alt ist als das Königthum selbst. Jedenfalls stehen diese Erzählungen weit $a b$ von der Zeit, von der sie handeln, und selbst wenn man die darin ausgesprochenen Ideen der vorexilischen

1) Dasselbe gilt z. B. auch von einer Erzählung wie 2 Kön. 1; 1. Sam. $13,7-15$. 
Zeit zuschreiben könnte, so wäre von da noch ein weiter Schritt zu der Annahme, dals sie in der vorköniglichen Zeit realisirt waren. Ueberdies sind wir hier immer noch nicht beim Priestercodex angelangt. Der deuteronomistische Gegensatz gegen die volksthümliche Form der Religion verschärft sich hier freilich zu einem solchen gegen das gesammte nationale Volksthum, für Israel wird principiell eine wesentlich andere Lebensform postulirt als für die übrigen Völker. Indessen ist auch hier noch deutlich, dafs die Vorstellung einer selbständigen geistlichen Theokratie sich erst im Verlaufe der israelitischen Geschichte gebildet hat. Israel erscheint, hier als die Gemeinde des Gesetzes, auf das deuteronomische Gesetzbuch wird gelegentlich (1 Sam. 10, 25) angespielt. Aber das Gesetz schwebt doch nur wie ein Hauch über diesen Erzählungen, concret wird seine Existenz in ihnen in keinerlei Organen oder Instituten deutlich. Es fehlt ein Centralheiligthum (denn Rïcht. 20, 27 b. 28 a ist offenbar eine Glosse; vgl. 20, 1. 21, 19 ; 1 Sam. 7, 9.17), deshalb ist die einheitliche Gemeinde des Volkes Gottes Richt. 19-21 ein Schemen und völlig schattenhaft ist auch die Gestalt Samuels in den genannten Stücken des Samuelisbuches. In Wahrheit ist sein Widerstand gegen die Stiftung des Königthums und weiterhin die selbständige Theokratie, die er vertritt, nichts als eine abstract principielle Zuspitzung, Antedatirung und Hypostasirung des Gegensatzes, in den die Prophetie je länger je mehr zum Königthum und überhaupt zum nationalen Volksthum trat. Das heifst aber nichts anderes, als dals die selbständige Theokratie des Gesetzes sich aus der Prophetie entwickelt hat. Die Analyse des Samuelisbuches beweist, dafs sogar der Samuel von 1 Sam. 15. 28 der ursprünglichen Ueberlieferung fremd ist, noch später ist der von 1 Sam. 16 eingetragen. Ebenso deutlich sind die Stücke 1 Sam. 7. 8. 10, 17 ff. 12 in den Zusammenhang von 1 Sam. 9. 10. 11 erst nachträglich eingeschoben. Hier 
sind die älteste und dic späteste Auffassung Samuels zu einem höchst übel disharmonirenden Ganzen verquickt, in der Mitte zwischen beiden stehen jene anderen beiden Stücke. Uebrigens stützt sich die Kritik, indem sie die Benutzung der deuteronomistischen und anderer verwandten Elemente der historischen Bücher für die Construction der älteren Geschichte ablehnt, keineswegs nur auf literarkritische und religionsgeschichtliche Untersuchungen und Erwägungen, wie z. B. aut die Annahme, dafs das Deuteronomium in der zweiten Hälfte des 7. Jahrhunderts entstanden sei. Ihre Abweichung von den übrigen Stücken ist eine so allseitige, dafs sie schon nach den allgemeinen Gesetzen jeder Geschichtsforschung für Erzeugnisse späterer Zeit gelten müssen.

Die Differenz zwischen den Vertretern der Graf' schen These und deren Gegnern scheint mir in hohem Grade eine methodische und bei manchen im letzten Grunde allerdings auch eine theologisch principielle zu sein. Bei der. Untersuchung nach dem Alter des Priestercodex ist zunächst doch wohl zu fragen, von welchem Zeitpunkt ab er nachweislich in die Geschichte eingetreten ist. Das ist er notorisch erst seit Esra. Vorher ist keine Spur von ihm nachzuweisen. Danach ist die weitere Frage sofort dahin zu stellen, ob der Priestercodex nicht überhaupt erst in der Zeit Esras entstanden sei. Ist seine Entstehung in dieser Zeit begreiflich, so würde dieselbe selbst dann hier als wahrscheinlich anzusetzen sein, wenn sie übrigens auch in früherer Zeit denkbar wäre. So liegt die Sache aber keineswegs. .

Während die exilische resp. nachexilische Entstehung mindestens als durchaus möglich erwiesen ist, fehlt für die Annahme der vorexilischen Entstehung jeder Anknüpfungspunkt ${ }^{1}$ ). In der vorexilischen Religionsgeschichte, über

1) Dt. $14=$ Lev. 11 kann durchaus nicht für einen solchengelten. Es ist nicht nur möglich, sondern sogar selr wahrscheinlich, dafs ein- 
die wir durch die historischen und prophetischen Bücher ausreichend informirt sind, ist keine Phase zu entdecken, aus der seine Entstehung verständlich wäre, geschweige denn, dafs die Annahme seiner vorexilischen Existenz uns das Verständnifs irgend einer Erscheinung der älteren Geschichte erleichtern würde. Im Gegentheil, er steht dem Verständnifs der letzteren überall im Wege. Uebrigens áber mufs jeder, der die Geschichte der israelitischen Tradition auch nur einigermalsen kennt, zugestehen, dafs die Zurückführung dieser Gesetze auf Mose nicht den Ausgangspunkt der Untersuchung abgeben darf. Wenigstens haben diejenigen, welche den Priestercodex 500 Jahre nach Mose ansetzen, kein Recht sich auf die entgegenstehende Tradition zu berufen, wenn Andere noch 500 Jahre tiefer hinabgehen. Trotz dieses Sachverhalts stellen die Gegner von vornherein die Frage, ob nicht trotz der historischen und prophetischen Bücher die vorexilische Abfassung in abstracto möglich sei, und meinen die Graf'sche These widerlegt zu haben, indem sie die postulirte Möglichkeit vermittels völlig abstracter Hypothesen construiren. Solche Luftgebilde ohne Fleisch und Bein sind freilich auch nicht todtzuschlagen. Für die biblische Geschichte hätte es nun freilich gar nichts zu bedeuten, ob der Priestercodex blofs literarisch vor dem Exil. da war oder nicht, da er nachweislich vor dem Exil gar keinen Einflufs geübt hat. Nachdem man ihn aber zunächst blofs literaturgeschichtlich vor dem Exil untergebracht hat, soll er dann aller un-

zelne Capitel des Cultus und der Sitte schon vor dem Exil schriftstellerisch entwickelt waren. Eine lediglich mündliche Ueberlieferung der priesterlichen Thora, die auch schon vor dem Exil theilweise einen ritualen Charakter hatte, ist kaum denkbar. Aber darauf kommt es eben nicht an, sondern auf die Totalität des Priestercodex d. h. auf die systematische Entwickelung des Cultus und der Sitte als göttlicher Institutionen und eines geistlichen Israel. 
zweifelhaft echten Ueberlieferung zum Trotz doch wieder für die Secle des vorexilischen Israel gelten und dem Inhalt nach'gar wesentlich mosaisch sein. Das heifst aber nichts anderes, als die wissenschaftliche Methode, die man übrigens selbst als die Richtschnur der theologrischen Arbeit fordert, auf den Kopf stellen.

In der That ist dieser methodische Fehler zu grofs, um für zufällig gelten zu können. Er beruht auf tieferliegenden Gründen. Und zwar ist es nicht nur der fortwirkende Einfluls Ewald's und de Wette's, das Gewicht der wissenschaftlichen Tradition, was hier der richtigen Erkenntnifs im Wege steht, es sind vielmehr dogmatische oder doch religiös-ästhetische Dispositionen. Der Widerspruch gegen die Graf'sche These ist von verschiedenen Seiten, die doch sonst das Recht und die Pflicht der theologischen Wissenschaft anerkennen, in einer Weise erhoben, die hierüber keinen Zweifel läfst. Man wird von den Gegnern Graf's deshalb keine völlig objective Würdigung seiner Argumente erwarten dürfen. Verständlich sind allerdings diese Stimmungen gegenüber der neuesten Wendung der Kritik. Was man gewöhnlich die menschliche Seite der Bibel nennt, erscheint danach um ein Stück breiter als zuvor, die göttliche wird scheinbar mehr und mehr verengt. Im Interesse der praktischen Verwerthung des A. T. in Kirche und Schule kann sich deshalb jeder Wohldenkende einer gewissen Beklemmung wohl nicht erwehren. Indessen ist dadurch doch nur deutlicher geworden, was seit langem am Tage lag, eben die Mängel der gewöhnlichen Behandlung des A. T. und der Bibel überhaupt in der kirchlichen Praxis treten um so klarer vor Augen. Ebenso könnte doch vielleicht auch der, welcher sich in seinen theologischen Grundanschauungen durch die kritischen Positionen Graf's behelligt fühlt, in jenen und nicht in diesen den Fehler zu suchen haben. Ich irre mich wohl nicht, wenn ich den Widerwillen gegen die Graf'sche 
These zu einem guten Theil aus einer Ueberschätzung des alttl. Opfercultus ërkläre, die wiederum in einer. Ueberschätzung des Bildes begründet ist, unter dem im N. T. die Bedeutung des Todes Christi so vielfach zum Ausdruck kommt.

II.

Die jüdische Theokratie, d. h. die Herrschaft des Gesetzes, ist als das vorläufige Resultat der vorexilischen (und exilischen) Geschichte Israels zu begreifen. Man hat diese Betrachtungsweise als pantheistisch oder gar als naturalistisch bezeichnet, indessen möchte es leicht zu zeigen sein, dafs sie weit mehr als die herkömmliche dem Glauben an die göttliche Weltregierung gerecht wird. Man hört gelegentlich wohl die Frage, ob die israelitische Religion in gewissen Stadien ihrer Geschichte nicht ein Bild geboten habe, wie andere Religionen des Alterthums auch, so dafs sie möglicherweise das Schicksal dieser hätte theilen können. .Diese Frage ist keineswegs so kurzab zu verneinen, wie das vielfach geschieht. Die israelitische Religion hat in der That solche Stadien durchgemacht, an denen wenigstens für unsere Betrachtung und Kenntnifs diese Möglichkeit vorlag. Im Gegentheil ist es mir unverständlich, wenn man andererseits das Bedürfnifs zu empinden scheint, die Anfänge der israelitischen Religion so vorzustellen, dafs die nachfolgende Entwicklung sich als deren nothwendige Folge ergiebt. Freilich erwarten wir schon in den Anfängen Israels diese und jene Eigenthümlichkeit zu entdecken, die auf den beispiellosen Ausgang seiner Geschichte hinweist, doch darf man keine irgendwie bestimmte Vorstellung davon von vornherein mitbringen. Denn hier handelt sich's gar nicht um eine künst- 
liche Construction des alten Israel vermittels hypothetischer Combinationen, sondern lediglich um eine sorgfältige Verwerthung des Kernes der älteren Geschichtsbücher einschliefslich des Pentateuch sowie der älteren Propheten. An urkundlichem Material besitzen wir vollauf genug, um ein Bild vom alten Israel zu entwerfen, das in allen Hauptzügen auf allgemeine Anerkennung Anspruch machen kann.

W ellh a u sen hat wohl zuerst gezeigt, dafs man die Geschichte der israelitischen Religion nur daraus recht versteht, dals sie mehr als alle anderen Nationalreligion war. Was man ihr gewöhnlich zum Vorwurf macht, ihr entschiedener „Particularismus", war eben ihre Stärke und ihr Vorzug. Das alte Israel erscheint uns als ein höchst naturwüchsiges Volk, das sich vor allen Dingen als Nation fühlte und als Nation lebte. Es konnte in der That wohl nicht anders sein, seine Schicksale brachten das mit sich. In einem fast ununterbrochenen Kampf um die nationale Selbstbehauptung verlief seine ganze Geschichte, in Sonderheit die ältere. Es lebte in einem Lande, das aus allen nur denkbaren Gründen das Ziel unaufhörlicher Angriffe war, es bedurfte der energischesten Kraftanspannung, wenn das Volk nicht zerrieben werden sollte. Israel behauptete sich, mit der Noth und Gefahr wuchs immer wieder die nationale Kraft, der tiefsten Erniedriguing folgte jedesmal eine um so glänzendere Erhebung. Dies energische Nationalbewufstsein datirte aber schon von den Anfängen des Volkes her. Die Stämme Israels hatten sich mit Glück aus der ägyptischen Knechtschaft befreit und nach längerem Aufenthalt in der Wüste das Land Kanaan erobert. Schon die Entstehung des Volkes war unter Bedingungen erfolgt, die für die Ausbildung jenes Bewufstseins von grofser Bedeutung waren. Damit steht die Thatsache, dafs Israel eigentlich erst durch Saul und David ein einheitliches Volkwurde, keineswegs.im Widerspruch. Die Stämme hatten sich von jeher als eine Einheit gefühlt, dafs sie sich erst so 
spät und nur unter dem Druck der bittersten Nothwendigkeit zu einem Volke zusammenschlossen, haben wir z. Th. wohl wiederum aus einem grofsen Kraftgefühl zu erklären, wenngleich sich von selbst versteht, dafs ein Nomadenvolk keine staatliche Einheit bilden kann und auch nach dem Uebergang zum sefshaften Leben nicht sofort von der alten Ungebundenheit lärst.

In der That müssen wir den Anfang der Geschichte Israels vom Auszug aus Aegypten datiren, seitdem gab es ein Israel. Auch wenn wir von der glücklichen Flucht aus Aegypten, dem Durchzug durch das Rothe Meer, der Besiegung der Amoriter jenseits des Jordan nichts wüfsten, wir mülsten derartiges supponiren, um die nachfolgende Geschichte zu begreifen. Denn woher stammte das Gefühl der Zusammengehörigkeit, das die Stämme. später in Kanaan verband? Blutsverwandtschaft bestand zwischen ihnen, aber sie war doch in mancher Beziehung nicht weit her und hat in Sonderheit in diesem Fall nicht viel bedeutet. Wenn irgendwo, dann wurde hier durch andere Factoren die Volksentstehung bedingt. Die Begriffe Israel und Jahve waren es, in denen die Stämme sich eins fühlten und die hier wirklich volk- und staatbildend waren. Vor der Eroberung Kanaans lag eine gemeinsame grofse Geschichte, aus der Israel und Jahve stammten, die Erinnerung daran hielt die Stämme zusammen, dort war in Wahrheit der Grund zu allem Späteren gelegt.

Israels Gottesbewulstsein fiel zunächst durchaus mit seinem Nationalbewulstsein zusammen. Jahve war Israels Gott geworden, als Israel entstand, und umgekehrt war Israel dadurch ein Volk geworden, dafs Jahve sein Gott wurde. Jahve und Israel waren ohne einander nicht denkbar, bis zu einem gewissen Grade waren sie geradezu identisch. Natürlich aber war Jahve der Aeltere von beiden, Israel war in ihm begriffen und nicht umgekehrt, so entschieden auch Israels Glück als das Ziel seines Waltens galt. Jahve 
war es, der die grolsen Thaten Israels vollführte, sein wunderbarer Geist war es, der in den Helden Israels so Grofses wirkte, das nationale Bewufstsein war sofort auch Gottesbewufstsein. So hat sich in Israel das lebendigste Grottesbewufstsein entwickelt, das die alte Welt kennt.

Als Gott Israels offenbarte Jahve sich vor allen Dingen im Kriege, das war an sich natürlich und auch der Name Israel weist darauf hin. Indessen war Jahve als Nationalgrott auch noch mehr. Wenngleich das nationale Bewufstsein sich am stärksten im Kriege regte, so war es doch auch im Frieden vorhanden. Das Hirtenvolk, das sich unter den Kanaanitern festsetzte, wufste sich in seiner Art wesentlich verschieden von den Letzteren. Gewifs mufsten die Sieger in gewissem Grade die Cultur der Besiegten annehmen, aber dennoch blieb Israel eben israel. Es war stolz auf die unverdorbene Sitte der Väter und suchte sie festzuhalten. Auch nach dieser Seite bekam das nationale Bewufstsein gewifs die stärksten Impulse durch die beständigen Kämpfe, in denen das Volk sich gegen anders gesittete zu behaupten hatte. Der sittliche Charakter der hebräischen Gottesvorstellung ist dadurch wohl wesentlich gefördert. In gewissem Malse wird freilich jede Nationalreligion von Haus aus einen sittlichen Charakter tragen. Namentlich gilt das von Israels Verwandten am Rande der Wüste, wie das aus vielen Stellen des A. T. und auch aus dem Buche Hiob hervorgeht. Wo sich ein lebendiges Gottesbewufstsein national ausbildet, da steht überall auch die innere Volksordnung und Sitte in ihrem gesammten Umfange unter göttlichem Schutze. Namentlich gilt Gott hier überall als der Wächter von Recht und Billigkeit, zunächst innerhalb des Volks. Merkwürdig ist freilich die Entschiedenheit, mit der der Hebräer auch über den Rahmen der Nation hinaus das Recht des Mitmenschen, nicht nur vom. völkerrechtlichen, sondern vielmehr noch vom humanen Gesichtspunkte aus dem göttlichen Schutze unter- 
stellte. A.ber das ist nur eine Folge davon, dafs Israel das nationale Recht und die nationale Sitte in so enge Verbindung mit der Gottheit setzte. Der Unterschied ist also auch hier wiederum nur der, dafs in Israel ungleich intensiver vorhanden war und sich immer höher entwickelte, was anderswo verkümmerte und unterging. Das Institut der Thora mag wesentlich dazu mitgewirkt haben, obwohl Institute ohne den lebendigen Geist todt sind und die Thora, wie der Name anzudeuten scheint, ursprünglich wohl weniger auf die Gerechtigkeit als auf die Weisheit Gottes reflectirte. Denn was die Güte der sittlichen Gesinnung anging, so kannte die ältere Zeit hierin kaum einen Unterschied zwischen Gott und dem volksthüm= lichen Gewissen.

Im Allgemeinen hatte man anfangs. auch kein klares Bewufstsein von einer Differenz zwischen Jahves Willen resp. dem öffentlichen Gewissen und dem öffentlichen Leben. Gewifs war der Begriff der Sünde als des gottwidrigen Handelns dem Volke zu keiner Zeit fremd, aber sie wurde in alter Zeit mehr als eine Verfehlung der Einzelnen, denn als eine solche des ganzen Volkes empfunden, und das Vergehen gegen die Gottheit ward nicht minder als ein Verstofs gegen Israels gute Art gefühlt. Der Vergeltungsglaube der alten Zeit war deshalb auch wenig entwickelt. Fehlen konnte er nicht. Jahve strafte gewifs die Uebertretung seines Willens und belohnte den Gehorsam, aber man dachte nicht daran, dals sein Verhalten gegen die Menschen regelmälsig aus dem Verhalten der Menschen gegen ihn $z u$ erklären sei. Im Grolsen und Ganzen sorgte Jahve für Israels Glück, aber seine gnädige Fürsorge liefs in Zeiten der Noth oft lange auf sich warten. Er wirkte alles, Glück und Unglück, weshalb das letztere, das schien oft unerklärlich. Trotz seiner Sympathie für Israel war seine Stimmung Wechseln unterworfen, die unberechenbar waren. Eben dieser Umstand giebt der ältesten 
Periode der israclitischen Religionsgeschichte ihre eigenthlimliche Signatur. Gnade und Zorn empfand man um so leblaftér, weil ihre Ursachen unbekannt waren. So mächtig die Nation sich in grofsen Zeiten von dem Beistand ihres Gottes gehoben fühlte, so stolz und zuversichtlich sie meistens darauf vertraute, so furchtbar fühlte sie zu anderen Zeiten den Druck seines Zorns, wie die schreckliche Laune eines allmächtigen Tyrannen. Da wagte man nicht mehr ihm zu opfern, ja nicht einmal seinen Namen zu nennen.

Aber solche Zeiten gingen vorüber, in der höchsten Noth stellte Jahve sich doch immer wieder als Israels Freund ein, sein Geist fiel auf diesen und jenen, der im Namen Jahves sein Volk zu den Waffen rief und es zum Siege führte. Der Noth der Richterzeit machte Jahre dadurch ein Ende, dals er die Stämme unter einem Könige vereinigte. Der Erfolg war ungeheuer. Saul und David befreiten Israel von den Philistern und in wenigen Jahren wurde das vor Kurzem noch so ohnmächtige Israel das mächtigste Volk Syriens. Wiederum hatte das Volk auf das Wunderbarste erfahren, was sein Gott vermöge und wie Grolses er mit ihm vorhabe. Aus der ersten Königszeit datirt vor allen Dingen Israels Glaube an seine Zukunft und an seinen Beruf. Wenigstens für Juda war das der Höhepunkt der israelitischen Geschichte. Hier lag die grofse Vergangenheit, auf die man später in trübseliger Gegenwart stoìz zurücksah, im Rückblick auf sie ging man zuversichtlich einer grolsen Zukunft entgegen, von hier entlehnen die Propheten die Farben der messianischen Weissagung, weil diese überhaupt hier wurzelt.

Zugleich datirt aber wohl gerade von der Stiftung des Königthums das Bewufstsein von dem Gegensatz zwischen Jahve und Israel. Jetzt war Israel vielmehr als zuvor eine greitbare Grölse geworden, erst das geeinigte Volk war eigentlich als eine Persönlichkeit vorstellbar, 
deren Thun und Lassen man an dem Willen Jahves messen konnte. Zunächst handelte für Israel der König, das ganze Volk mufste zuweilen für seine Sünden büfsen. Wir irren vielleicht nicht, wenn wir annehmen, dafs man erst seit dieser Zeit sich gewöhnte, aus öffentlichem Unglück auf bestimmte Sünden des Volkes zu schlief'sen. Sodann brachte das Königthum wie jeder Culturfortschritt nicht nur im Guten, sondern vielmehr noch im Bösen manches mit sich, was mit dem altisraelitischen Wesen in Widerspruch stand, und dieser Widerspruch zwischen dem öffentlichen Leben und dem Volksgewissen hatte zur nothwendigen Folge, dafs Jahve und Israel im Bewufstsein mehr und mehr auseinandertraten. In gewissem Mafse war jener Widerspruch aber schon lange vorher damit gesetzt, dal's das Hirtenvolk bei der Eroberung Kanaans ein Bauernvolk wurde und die kanaanitische Cultur, theilweise auch den kanaanitischen Gottesdienst annahm. Seit der Eroberung des Landes gab es in Israel selbst einen Widerstreit israelitischen und kanaanitischen Wesens, noch viele Jahrhunderte später schien der Nomadenstand manchem als der allein Gott wohlgefällige. Indessen scheint dieser letztere Gegensatz in der älteren Zeit doch nicht dieselbe Rolle gespielt zu haben wie der erstere, Jahve kam in alter Zeit wenigstens schärfer mit dem Königthum in Conflict als mit dem entarteten Volksthum. Der Abfall der zehn Stämme vom Hause David ging grofsentheils hervor aus einer wenn auch unklaren Reaction des volksthümlichen Wesens gegen die Neuerungen des Königthums, der Prophet Ahia von Silo hat wohl wesentlich in diesem Sinne gewirkt.

Samuel ist der erste Prophet, von dem wir hören, er hat den Saul zu seiner kühnen That inspirirt. Ursprünglich bewirkte der Geist Jahves noch unmittelbarer die nationale That, man kann sagen, dals in der ältesten Zeit die Richter das sind, was später die Propheten. Auch Mose ist vielmehr mit jenen als mit diesen zusammenzu- 
stellen. Immerhin ist es ein Fortschritt, wenn der Führer des Volks und der Trüger des Geistes Jahves als zwei verschicdenc Personen nebeneinanderstehen, wie schon Barak und Debora. Uebrigens kümmerten sich die Propheten von vornherein nicht nur um die grofsen nationalen Angelegenheiten, sóndern ebenso sehr um das eigentliche Volksleben bis hinunter in die kleinen Dinge der Alltäglichkeit. Ueberall liefsen sie sich um Rath und Hülfe angehen, aber auch ungefragt erscheinen sie als kräftige Verfechter der göttlichen Forderungen gegenüber dem V.olk wie gegenüber dem Einzelnen. In mancher Beziehung war ihre Aufgabe sehr ähnlich der des Priesters, des ständigen Vertreters Jahves beim Volke. Ja es scheint, dafs Priester und Prophet im Alterthum vielfach ein und dieselbe Person waren (vgl. Wellh. Gesch. I; 412). Späterhin sind sie regelmälsig Verbündete, es fehlt für die Annahme einer priesterlichen und einer prophetischen Richtung im alten Israel in der That jeder Anhalt. Die Sache Jahves wurde aber natürlich viel entschiedener und kräftiger von den Propheten geführt, schon deshalb, weil der Priesterstand immerhin von König und Volk abhing, vor allen Dingen deshalb, weil die Sache Jahres eine lebendig werdende war. Im Reiche Ephraim begegnet uns freilich auch ein geschlossener Prophetenstand, man hat aber wohl kein Recht, darin eine absichtliche Organisation des Widerstandes gegen das Königthum und die Entartung der Volkssitte zu sehen. Wenigstens scheinen diese Vereine älter zu sein als das Königthum, und was wir später über ihr Verhalten gegenüber dem Hause Omri hören, begünstigt jene Auffassung keineswegs. Immerhin ist es aber merkwürdig, dafs der Ausdruck Nabi den althebräischen Ro'e verdrängte, obwohl jener vielfach einen üblen Klang hatte. Das ist doch nur dann zu begreifen, wenn aus jenen Vereinen die gröIsten Propheten der älteren Königszeit hervorgingen. Auch ist es denkbar, dafs die Prophetenvereine sich zeit- 
weilig als die alleinigen Vertreter des ächten Jahveglaubens fühlten, wie das wohl von der Secte der Rekabiter anzunehmen ist.

Die Rekabiter sind als eine Reaction gegen die zunehmende Entartung des Volkslebens zu begreifen, es ist ebenso zu verstehen, wenn die Propheten Elia und Elisa mit der gröIsten Entschiedenheit den Kampf gegen den Baalsdienst aufnahmen. Seit Salomo hatten fremde Culte ungestört in Jerusalem bestanden, es scheint nicht, dafs die ältere Zeit daran einen Anstofs nahm. Es war also eine neue Forderung, die jene Propheten stellten, wenn dieselbe auch durch die neuerliche Einführung des phönicischen Baalsdienstes in Samaria veranlalst war. Innerhalb gewisser Kreise fanden diese Propheten Anklang, der Sturz des Hauses Ahab führte auch zur Ausrottung des Baalsdienstes. Freilich hatten Elia und Elisa das Haus Omri noch aus einem anderen Grunde bekämpft, sie verlangten Rache für den Mord Naboths, überhaupt aber trug der Kampf zum guten Theil wohl einen principiellen Character. Was diese Propheten gegen die bedeutendste Dynastie Israels aufbrachte, scheint hauptsächlich doch ein gewisser profaner Sinn gewesen zu sein, der die Ansprüche des prophetischen Worts ignorirte. Man kann sich des Eindrucks nicht erwehren, -dals hier wirklich die Gegensätze von geistlich und weltlich mit einander kämpften, so ungeistlich auch die Mittel waren, durch die Elisa triumphirte.

Allerdings scheint der Sieg der Propheten wenigstens für das Reich Ephraim von keinen nachhaltigen Folgen gewesen zu sein. Hatte Elisa gehofft, durch den Sturz des Hauses Omri die Lage der Dinge wesentlich zu bessern, dann hat er sich gründlich getäuscht. Der wichtigste Erfolg war vielleicht der, dafs man nun erst recht die Gröfse des Uebels kennen lernte, das man im Hause Omri bekämpft hatte. Mit der Ausrottung des phönicischen Baals- 
cultus. war wenig erreicht, da der Jahvecultus des Nordreichs nachgerade nicht vicl besser war als jener. Ueberdies abcr hatte das Haus Jehu zuletzt kaum einen Vorzug vor dem Hause Omri. Als man durch die assyrische Zuchtruthe auf die Sünden des Volkes aufmerksam gemacht wurde, da war das gesammte Volksleben in einem Grade entartet, dals man kein Heilmittel mehr sah. Wir haben freilich keinen Grund von der religiösen und sittlichen Bildung Ephraims gering zu denken, die uns erhaltenen Reste ephraimitischer Literatur erlauben das nicht. Indessen fordert doch die Thatsache eine Erklärung, dafs die neue Prophetie, die mit Amos beginnt, in Juda aufkam. Hosea, der dem Nordreich angehört, ist jenem gegenüber immerhin eine secundäre Erscheinung, bei aller Tiefe der Einsicht und der Empfindung hinterläfst seine Schrift doch den lebhaften Eindruck der Rathlosigkeit, mit der dieser Prophet in die Zukunft seines. Volkes sah. Sie ist eine merkwürdige Illustration der tragischen Thatsache, dafs mit dem Untergang des Reiches Ephraim auch das Volk von Ephraim aus der altt. Geschichte verschwindet.

Uebrigens ist auch der letztere Umstand für die richtige Auffassung der vorexilischen Geschichte von Bedeutung. Als Samaria zerstört wurde, hatte die Religion eben noch keine solche Selbständigkeit erlangt, dals sie den Untergang des Staates hätte überdauern können. Die Factoren, welche später nach dem Untergange Judas die Entstehung der jüdischen Gemeinde ermöglichten, haben sich wesentlich in dem einen Jabrhundert gebildet, das zwischen diesen beiden Ereignissen liegt. Es war nicht nur die judäische Prophetie, sondern vielmehr noch etwas anderes, was sich freilich im Anschlufs an diese Prophetie in Juda entwickelte. Damit soll keineswegs geläugnet werden, dals in Juda schon seit längerer Zeit gewisse Bedingungen vorlagen, die für den späteren Verlauf der Dinge bedeutungsvoll wurden. Die Bürger des kleinen 
Reichs, das seit Jahrhunderten nur eine untergeordnete Rolle gespielt hatte, konnten späterhin viel eher eine rein religiöse Gemeinde bilden und sich mit Ezechiel über das unnütze Rebholz trösten, das eben nur zum Verbrennen taugte. Wichtig wurde weiterhin auch, dafs am Tempel in Jerusalem seit Salomo ein mächtiges Priestergeschlecht amtirte.

Was aber zunächst die judäische Prophetie angeht, so ist ihr Emporkommen z. Th. gewils aus denselben Ursachen zu erklären, die den längeren Bestand des Reiches Juda begreiflich machen. Schon äufserlich war die Lage Judas weniger exponirt und seine inneren Zustände waren solider. So lebhaft die Theilnahme war, mit der man in Juda der das Reich Ephraim bedrohenden Gefahr zusah, man konnte den Gang der Dinge mit mehr Ruhe abwarten und sich auf den Sturm, der sich zuletzt auch auf Juda richtete, vorbereiten. Amos kündigt ja freilich nicht nur dem Reiche Ephraim den Untergang an, und selbst wenn das der Fall gewesen wäre, so würde das für das judäische Bewufstsein gewifs nicht viel weniger bedeutet haben, wie wenn er zugleich Juda bedrohte. Man hat allen Grund zu glauben, dafs Juda sich bis dahin nur als ein Stück von dem grofsen Israel fühlte. Erst durch Jesaja scheint das wesentlich anders geworden zu sein. Bemerkenswerth ist aber doch die Bedeutung, die Jerusalem schon für Amos hat. Von der grölsten Wichtigkeit war überhaupt, wie $V$ atke bemerkt hat, dafs die Vernichtung des ganzen Volkes sich schrittweise vollzog und dem Bewulstsein immer wieder Zeit gelassen wurde, das Geschehene zu verarbeiten und sich damit auf das Kommende zu rüsten.

Die unverglẹichliche Grölse, mit der die judäische Prophetie in der vorchristlichen Religionsgeschichte dasteht, soll damit nicht geschmälert werden. Einzigartig bleibt die Thatsache, dafs der kleine Gott von Jerusalem so gewaltig sein Haupt erhob, als die Assyrer und Chaldïer ihn 
scheinbar vernichteten, dafs er viclmehr die Vernichtung scines Volkes als scin eigenes Werk in Anspruch nahm, ehe sie eintrat, dafs er alle Miichte der Welt ohne Weiteres fuir seine Werkzeuge erklïrte, durch die er überall und vor allen Dingen an Israel Recht und Gerechtigkeit zur Geltung bringe. Mit principieller Schärfe wird dieser Gedanke gerade von den ersten Vertretern der neuen Prophetie ausgesprochen, aufs Schärfiste stellen sie den gerechten Gott und sein gottloses Volk einander gegenüber. Wellhausen hat Recht, wenn er sagt, dafs der Gott Israels, eben weil er der gerechte Gott war, sich in dem Conflict Israels mit den Weltmächten über alle Welt erheben konnte. Wir haben auch hier eine Consequenz, die wir aus der früheren religiösen Entwickelung begreifen, aber dennoch war es eine unvergleichliche Grofsthat des Glaubens, diese Consequenz zu ziehen, durch die doch auch für die Propheten Himmel und Erde ins Wanken gerieth.

Gewils bedeutet die prophetische Bufspredigt einen grolsen Fortschritt in der Erkenntnifs der Sünde. Die allgemeine Entartung schärfte zugleich das sittliche Urtheil, überdies, wollte der furchtbare Zorn Gottes gegen sein Volk erklärt sein. Freilich schliefsen die Propheten nicht nur von der drohenden Strafe auf die Sünde, sondern ebenso umgekehrt von der Sünde auf die Nothwendigkeit der Strafe. Auch lälst sich hierin bei den Propheten des siebenten Jahrhunderts im Vergleich zu denen des achten ein Fortschritt nicht verkennen, wie schon oben bemerkt wurde. Dasselbe gilt von den Vorstellungen der Propheten über die Aufhebung der Sünde, wie Duhm, wenn auch mit doctrinärer Uebertreibung, gezeigt hat. Denn so stark die Propheten betonen, dals das Verhältnifs Jahres zu Isràel nur ein bedingtes sei, -so kann es nach ihrer Meinung doch nie völlig gelöst werden, weil Jahve zuletzt Israel nicht entbehren kann. Zunächst erscheint es ihmen sogar undenkbar, dafs mit dem Reiche Israel auch das 
Reich Juda untergehen sollte. Jesaja und Micha stellen freilich auch das in Aussicht, indessen sprechen sie dabei doch immer wieder die Hoffnung aus, dafs es nicht dahin kommen werde. Die Religion schien unterzugehen, wenn auch Juda unterging, und in der That wäre das damals wohl der Fall gewesen. Jesaja urtheilte, dals eben auf Juda und dem Hause Davids die Zukunft beruhe, derselbe Prophet, der die furchtbarsten Strafgerichte für Juda weissagte. In beider Hinsicht wurden die Urtheile seines Glaubens wunderbar bestätigt und so gab er seinem Volke die Gewilsheit, dals mit Israel nicht Jahve vernichtet sei, sondern Juda an Israels Stelle trete. Die Menge verstand ihn freilich dahin, dals der Tempel in Jerusalem überhaupt nicht in die Hände der Heiden fallen könne, ein Mifsverständnifs, das für die Folgezeit verhängnifsvoll wurde, das aber andererseits doch auch die nothwendige Form des Glaubens an Jahve als den Gott Israels war. Deshalb ist Jesajas Glaube auch in dieser Gestalt von den wichtigsten Folgen für die ganze Zukunft geworden, sofern das Judenthum ohne den Berg Zion doch nicht denkbar wäre. Wie auf diesem einen Punkte, so erging es auf vielen anderen, die prophetischen Gedanken und Forderungen realisirten sich späterhin in einer Weise, die keineswegs den ursprünglichen Intentionen ihrer Urheber entsprach. Es ist ein Grundgesetz aller geschichtlichen Entwickelung, das hierin sich geltend macht und das an der aufserordentlichen Erscheinung der Prophetie um so viel deutlicher zu erkennen ist. Trotzdem haben die Propheten eine Umwandlung in ihrem Volke zu Wege gebracht, die erstaunlich ist. Wie das eine so mufs man auch das andere anerkennen.

Die Propheten erklärten den gesammten gegenwärtigen Zustand des Volkes für grundverderbt und weissagten die Zerstörung alles Bestehenden. Der weitaus grölste Theil des Volkes sollte nach Jesaja vernichtet Zeitschrift f. d. alttest Wiss Jahrgung 2. 1882. 
werden, nur cin klciner Rest sollte erhalten bleiben, aber auch der bediurfe einer völligen Umwandlung durch den gijttlichen Geist. Den Kern dieses zukünftigen Volkes Jahves meinte er schon um sich zu sehen. Es ist nun von grofser Bedeutung, dafs dic Propheten dies zukünftige Volk Jahves zunächst immer in der Form des nationalen Staates vorstellen, die herrliche Zukunft wird vor allen Dingren durch einen von Jahve wunderbar ausgerüsteten König herbcigeführt, der im Innern Recht und Gerechtigkeit herstellt und dann auch nach aufsen hin Israel zu Ehren bringt. Diese letztere Erwartung tritt aber namentlich im siebenten Jahrhundert in der Weissagung zurück. Wohl reden Jeremia und Ezechiel noch von dem messianischen Könige, aber mehr und mehr tritt Gott selbst an seine Stelle. Das unglückliche Ende Josias und seiner Reformation mag dazu beigetragen haben, aber in Wahrheit ist das nur eine nothwendige Folgerung aus der Grundanschauung der Propheten. Der zukünftige Staat hat für Jesaja vor allen Dingen den Sinn, dafs in ihm jeder Einzelue, besonders jeder Arme und Unterdrückte, sein Recht findet. Erwartet er nun im Grunde allein von einem wunderbaren Eingreifen Jahves die Herstellung eines solchen Staates, so ist das eben nichts anderes als die sittliche Weltordnung. Der wunderbare König, den Jesaja weissagt, hat freilich wohl noch eine andere Bedeutung. Gewifs kommt in diesen Weissagungen auch das Bewufstsein zum Ausdruck. was die einzelne Persönlichkeit in der Geschichte bedeutet. Aber dennoch war dieselbe in diesem Zusammenhang auf die Dauer nicht festzuhalten, dem Glauben an die gerechte Vergeltung. Jahves für jeden Einzelnen war der nationale Staat am Ende gleichgültig. „Ich will selbst meine Heerde weideu", sagt Jahve (Ez. 34, 10̄). Als der judäische Staat unterging und das Band zwischen Gott und Volk zerschnitten war, ging die Religion doch nicht unter. Durch die Propheten war sie eben mehr 
geworden als ein Verhältnifs zwischen Gott und Volk, sie war jetzt auch ein Verhältnifs zwischen Gott und dem einzelnen Menschen. Nicht nur das Volk, sondern auch der Einzelne erwartete jetzt von Gott sein Heil; dal's er es konnte, hatte er wesentlich den Propheten zu danken, die durch die ausschliefsliche Betonung des sittlichen Characters der Religion die Individuen verselbständigt hatten. So war es im Exil möglich, aus den Trümmern des alten Volkes eine Religionsgemeinde zu sammeln.

Auch für die Lebensformen der jüdischen Gemeinde ist in der prophetischen Zeit der Grund gelegt. Von Haus aus hatten die Propheten keineswegs die Absicht, die bestehenden Verhältnisse praktisch umzugestalten. Bessern konnte sie nur Jahve durch seine Strafgerichte und eine völlige Umwandlung des Volkes. Aber durch den Lauf der Dinge wurden die Propheten mehrmals dennoch gezwungen, reformatorisch in das Volksleben einzugreifen. Die von ihnen geweissagten Katastrophen traten ein, ohne dal's das Volk wesentlich ein anderes geworden wäre, da blieb nichts anderes übrig, als praktisch zu bessern, soviel man eben konnte. Denn durch die Erfüllung ihrer Weissagungen wurden die Propheten die Herren der Lage, sie konnten sich jener Aufgabe nicht entziehen, auch wenn sie gewollt hätten. Obendrein wollte ihnen selbst der Gedanke an den völligen Untergang des Reiches schwer eingehen und unter dem Eindruck der furchtbaren Schläge, die Juda trafen, milderte sich die Schärfe ihres Urtheils. Sie mufsten nun freilich die Staatsgewalt in Anspruch nehmen, mit Zwang und Gewalt sollte das Volk zu dem angehalten werden, was es freiwillig nie gethan hätte. Der Gegensatz. zwischen Prophetie und Volksthum erstreckte sich freilich auf alle Gebiete des Volkslebens, aber bald drehte sich der Kampf zwischen beiden vor allen Dingen um den volksthümlichen Cultus; der nach Form und Geist wesentlich heidnisch war. In der That lag hier 
der Lebensnerv des entarteten Volksthums. Ein Bilderdienst, der die Gottheit in hohem Grade mit ihrem Symbol identificirte, sowie der Glaube, dals die Stimmung Gottes durch Opfer und Gaben zu beeinflussen sei, das waren wohl die wichtigsten Hindernisse, dic bei der Menge einer besseren Erkonntnils im Wege standen. Obendrein war auf diesem Gebiete noch am ersten mit aufseren Yitteln etwas $\mathrm{zu}$ erreichen, und es ist wohl auf Jesajas Initiative zuruickzuführen, dafs der König Hiskia gegen den volksthümlichen Gottesdienst, vor allem gegen die Bilder einschritt. Das war der erste Schritt auf einem Wege, den man späterhin mit Consequenz einschlug.

Einstweilen begann damit aber erst der eigentliche Kampf. Unter Manasse erfolgte eine Reaction von Seiten des Volksthums, die freilich, wie Wellhausen bemerkt, keine einfache Wiederherstellung des Früheren war. Dem furchtbaren Ernst der Zeiten konnte sich auch die Menge nicht mehr verschliefșen, sie empfand den Druck des göttlichen Zorns und fühlte sich schuldig, sie suchte nun aber die Versöhnung in dem Grauen, das ihr die Raffinirtheit fremder Cultussitten bereitete. Nach dem Muster namentlich der Assyrer und Babylonier wurde der Cultus verfeinert und weitergebildet, besonders kam damals das Kinderopfer auf, man. stellte dem Jahve sogar die Himmelskönigin zur Seite. Für die völlige Entartung des Volksbewufstseins ist dies um so characteristischer, als die Menge gewils nicht daran dachte, von Jahve abzufallen. Die Propheten sahen dagegen in diesem Treiben den Gipfel der Gottlosigkeit, die Sünde Manasses war es nach späterer Meinung, was den Untergang Jerusalems unvermeidlich machte.

Wiederum gewannen die Propheten unter Josia Einflufs auf die Gemiüther, wahrscheinlich unter dem Eindruck, den der grofse Scythenzug auf die Judäer machte. Da wurde ein neuer Reformationsversuch unternommen, auf 
breiter Grundlage, für den Augenblick mit durchschlagendem Erfolg und für alle Folgezeit von den weittragendsten Wirkungen. Das Deuteronomium war nicht das älteste Gesetzbuch in Israel, man hatte schon seit längerer Zeit, in verschiedener Form und Rücksicht die priesterliche Thora schriftstellerisch aufgezeichnet. Der Unterschied ist der, dafs man im Deuteronomium überall die reformatorische Tendenz des ${ }^{-}$Verfassers herausfühlt, der das gesammte Volksleben umgestalten möchte, was im Bundesbuch durchaus nicht der Fall ist. Daraus ist überhaupt die Reformation Josias zu verstehen, dafs sie etwas wesentlich Neues war. Den göttlichen Willen an Israel auf einen Gesammtausdruck zu bringen und das Volk auf denselben zu verpflichten, das war in der That der einzig mögliche Weg, auf dem Israel zum Gehorsam gegen Jahve gebracht werden konnte. Freilich ist es ein eigenthümlicher Dualismus, der sich durch das ganze Buch hindurchzieht. Nirgends wird im A. T. so eindringlich wie hier die Liebe zu Gott als das Princip der Religion und die Erfüllung der Nächstenpflicht, des allbekannten göttlichen Willens als der allein wahre Gottesdienst gepredigt und doch muls dieser beredte Prediger zugleich als Gesetzgeber an die Gewalt appelliren, um durch gewaltsame Ausrottung des Götzendienstes für den wahren Gottesdienst Raum zu schaffen. Merkwürdig sind dabei namentlich auch die humanen Gesichtspunkte, unter die er den ganzen Cultus stellt. Man darf darin wohl mit $\mathrm{W}$ ellh a usen die bewufste Absicht nicht nur auf Veredelung des Gottesdienstes, sondern auch auf innere Umwandlung desselben erkennen.

Indessen haben diese prophetischen Elemente des Deuteronomiums am wenigsten Einflufs auf die damalige Zeit gehabt. Die Hauptsache war einmal die äufsere Reformation des Cultus, die Ausrottung des Götzendienstes und die Aufhebung der Höhen. Die Vernichtung der heidnischen Culte war freilich eine unvollkommene, innerlich 
waren sie damit noch nicht überwunden, dafs man mit Gewalt gergen sic einschritt. Aber das Letztere war jedenfalls im Geiste jener Zeit und es war für die Folgezeit von gröfster Bedcutung, dafs es uiberhaupt cinmal zu einer praktischen Auseinandersetzung zwischen israelitischem und heidnischem Cultus kam. $\mathrm{Ob}$ eine archiologisch correcte Scheidung gemacht wurde, war dahei unwesentlich, im Gegentheil machte die Aufhebung der Höhen einen tief gehenden Schnitt durch die überlieferte Cultussitte. Der Gottesdienst wurde damit von seiner natürlichen Basis losgerissen. Positiv wurde dadurch das Ansehen des jerusalemischen Tempels aufs Höchste gesteigert und in seiner Priesterschaft das lebhatteste Gefühl von der Bedeutung geweckt, die sie fortan für den Fortbestand der Religion hatte. Das einzige Heiligthum brachte dem Synkretismus gegenüber die Einzigkeit des Gottes Israels zur Anschauung und diente somit:gewifs wesentlich zur Consolidirung der Religion.

Nicht minder wichtig war die Schöpfung einer heiligen Schrift. Fortan hatte der Glaube an ihr einen Compals, an dem er sich orientirte, eine Stütze, die ihm blieb, wenn alle anderen zusammenbrachen. Die schriftliche Fixirung des göttlichen. Willens war bei der völligen Auflösung des volksthümlichen Bewufstseins ein Ding der Nothwendigkeit. Concret und objectiv lag jetzt die Aufgabe vor, an deren Lösung die Frömmigkeit zu arbeiten hatte, wenn sie der göttlichen Hülfe gewifs sein wollte. Man kannte nun den Weg zum Heil, den die Menge doch unmöglich in ihrem inneren Bewufstsein finden konnte. Dies Princip war das Bedeutungsvolle und zunächst das geschichtlich Werthrolle. Dabei ist es gleichgültig, ob das Gesetz bald einen ganz anderen Inhalt gewann, als der Deuteronomiker beabsichtigt hatte. Sein Werk, das ein Gesetzbuch sein wollte und doch den Menschen an sein eigenes Gewissen wies, konnte es auf die Dauer am wenigsten sein. 
Jeremia sah freilich weiter. Gerade darin beweist er sich als der gröfste Prophet, dafs er schon das Ende der Entwicklung voraussah, die eben in seiner Zeit ihren Anfang nahm. Ihn empörte es, dafs die Menge nun mit grölserem Fanatismus denn je auf den Tempel vertraute, dafs sie jetzt, wo sie das Gesetzbuch hatte, auf die prophetische Stimme nicht mehr hören wollte, er wollte auf' einen neuen Bund hoffen, in dem Jedermann Jahves Gesetz im Herzen trug. Das war freilich das letzte Ziel dieser Geschichte, aber der Weg dahin war weit, viel weiter als Jeremia ahnte. Im Grunde hat er selbst davon ein Bewufstsein, wenn er von der Unverbesserlichkeit des Volkes redet, oder wenn er an den Gehorsam gegen das Sabbathsgebot die höchsten Verheilsungen kniipfen will. Es kam eben auf eine Erziehung des Volkes an. Ueberhaupt gilt von der Prophetie, was Vatke besonders von Deutero-

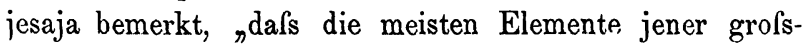
artigen Anschauung durch den gewaltigen Gegensatz der damaligen Zeit und die ungewöhnliche Aufregung, welche das religiöse Bewufstsein durch Leiden und Entsagung, Hoffnung und ringenden Glauben erfahren hatte, ans Licht gerufen wurden. Daher traten manche Seiten vor die ahnende Anschauung, welche für das allgemeine Selbstbewufstsein keine Wahrheit und Realität hatten, und späterhin, als ein gewöhnlicher Lauf der Dinge hergestellt war, in den Grund des Geistes zurückgingen" (S. 533).

Die grofse Bedeutung, die Jeremia trotzdem in seiner Zeit gehabt hat, braucht kaum erörtert zu werden. Haben die Propheten überhaupt die Religion dadurch gerettet und vergeistigt, dafs sie Namens der Religion den Untergang des Staates weissagten, so ist das vor allen Dingen von Jeremia geschehen. Den Kampf zwischen Prophetie und Volk hat er wie kein anderer mit Einsetzung seiner Persönlichkeit gefochten und zum Ende geführt. Der fromme König Josia ging nach langer glücklicher Regie- 
rung elend unter. Er, dor Vollstrecker des göttlichen Gesetzes, der wie kein anderer auf die Hülfe Jahves Anspruch zoi haben schien, wagte den Kampf mit Pharas Neko und bei Megiddo verlor er mit der Schlacht das Leben. Damit fiel auch sein Werk, die deuteronomische Reformation. Der Gehorsam gegen das prophetische Gesetz schien am Ende nicht gefruchtet zu haben, im Gegentheil, das Unglück Judas brach nun erst recht herein und das Volk meinte später gar, das sei dadurch verursacht, dafs man seit Josia der Himmelskönigin nicht mehr räucherte. In der That gewann nun die Volkspartei wiederum die Oberhand und blieb darin bis zu Jerusalems Untergang. Und nun erreichte der Kampf zwischen Prophetie und Volksthum seinen Höhepunkt. Nicht lange nach Josias Tode trat Jeremia mit der kategorischen Ankündigung von Jerusalems Untergang hervor, er bezeichnete die Chaldäer als das Werkzeug, wodurch Jahve das letzte Gericht an sèinem Volke vollziehen würde: Zwanzig Jahre gingen freilich noch darüber hin, aber unentwegt weissagte Jeremia immer wieder den UTntergang des Reiches und der Stadt. Ein furchtbarer Sturm erhob sich gegen ihn, fast allein stand er dem 'ganzen Volke gegenüber. Mit dem wüthendsten Hals ward er als Volksverräther angefeindet, die schwersten Verfolgungen brachen über ihn herein, ein über das andere Mal kam er in die äufserste Lebensgefahr. Und noch schwerer als diese äufseren Kämpfe waren die inneren, die Jeremia durchzumachen hatte. Der Gedanke an den.Untergang seines Volkes war ihm selbst entsetzlich, in sich selbst hatte er den furchtbaren Todeskampf durchgemacht, in dem sich Leib und Seele des alten Israel schieden. Aber aus der tiefsten und schwersten Verzweiflung erhob er sich zur kühnsten und gewissesten Hoffnung und wenn auch in anderer Art, so zeigte sich bei ihm doch in ähnlicher und noch grofsartigerer Weise als bei Jesaja, was die einzelne Persönlichkeit in der Geschichte 
bedeutet. Sein Gott rettete ihn aus allen Gefahren, die ihn umgaben, allen Nachstellungen der Feinde zum Trotz ward er erbalten bis zu Jerusalems Zerstörung, ja darüber hinaus - ein sichtbares Wahrzeichen für die Wahrheit des Gottes, den er predigte. Er erlebte seinen Triumph, denn Jerusalems Zerstörung war der endgültige Sieg seiner Sache. Im fanatischen Vertrauen auf Jahves Hülfe wagte das kleine Juda zweimal den Kampf mit der babylonischen Weltmacht und dieser Kampf endete wie Jeremia vorausgesagt hatte. $\mathrm{Da}$ erlag der volksthümliche Jahve dem prophetischen, der falsche dem wahren. Ein nicht unbedeutender Theil des Volkes, sowohl von denen, die im Lande zurückblieben, als auch von denen, die es freiwillig. oder unfreiwillig verliefsen, verlor sich freilich im Heidenthum, aber ein anderer unterwarf sich nun doch den Propheten und konnte das in der Hoffnung auf bessere Zeiten, die derselbe Jeremia so zuversichtlich aussprach.

Von dem Eindruck, den im Alterthum der Untergang eines Volkes auf die übrig bleibenden Glieder desselben machte, können wir uns wohl kaum eine annähernde Vorstellung machen. Nach dem A.T. wurde er als ein Sterben empfunden. Die Thatsache, dafs die Judäer durch den Untergang ihres Staates hindurch ihr Selbstbewufstsein bewahrten, ist beispiellos und zu ihrer Erklärung sind deshalb gewifs alle Umstände herbeizuziehen, die dazu tauglich erscheinen. Neben allem, was im Vorstehenden erörtert ist, möchte deshalb die Art und Weise, in der sich der Untergang Judas vollzog, unsere Aufmerksamkeit verdienen. Ueberhaupt war der Untergang des gesammten Israel ein allmäliger, er erfolgte in einer Reihe von Ereignissen, die sich auf einen Zeitraum von anderthalb Jahrhunderten vertheilen. Als das Reich Ephraim und mit ihm der weitaus grölste.Theil des alten Israel von den Assyrern vernichtet wurde, blieb Juda wunderbar erhalten. Im Rückblick auf diese ganze Kette von Thatsachen mulste 
froilich dio Nothwendigkeit des Untergangs dem Bewufstscin um so mehr cinleuchten, aber andererseits wurde es von dem letzten vernichtenden Schlage nicht überrascht, man hatte sich darauf vorbereiten können. Auch Juda fring nicht auf einmal unter. Zehn Jahre vor der Zerstörung Jerusalems hatte Nebukadnezar mit dem Könige Jojachin 10000 Judiier nach Babylonien werggeführt, das war die Aristokratie und wohl auch der geistige Kern des Volkes, im Allgemeinen waren schon damals nur geringe Leute im Lande zurückgeblieben. Die Chaldïer hatten offenbar gehofft, das seiner Weisel beraubte Völkchen werde sich nun ruhig halten. So war der Untergang des alten Jerusalem eigentlich schon eingetreten, ehe die Stadt zèrstört wurde. Es ist nicht unwahrscheinlich, dafs Ezechiel, der mit Jojachin abgeführt war, eben dadurch Prophet und von der Nothwendigkeit der völligen Vernichtung Judas überzeugt wurde. Die verbannten Aristokraten hofften frejlich, dafs die Stadt erhalten bleiben und sie nach Jerusalem zurückkehren würden, eben weil der Tempel noch stand, und sie litten es nicht, dafs Ezechiel öffentlich die Zerstörung der Stadt weissagte. Aber was dem Propheten wenigstens im" "Stillen eine Wirksamkeit ermöglichte, war der Antagonismus, der zwischen den verbannten Aristokraten und dem in Jerusalem zurückgebliebenen Volke bestand. Aehnlich wie Jeremia verhiefs er den Ersteren, dafs sie nach Jerusalems Zerstörung dorthin zurückkehren würden (Ez. 11). Man sieht aus Ez. 14, dafs dieser Antagonismus noch nach der Zerstörung Jerusalems fortbestand, als ein zweiter und, zwar kleinerer Zug von Deportirten in Babylonien angelangt war. Ezechiel spricht die Hoffnung aus, dafs die Grola Jojachins sich über den Untergang der Stadt trösten werde; 'wenn sie die Gottlosigkeit dieser ibrer neuangekommenen Brüder sähe. Ob dieser Gegensatz späterhin in Exil eine Rolle gespielt hat, läfst sich bei dẹm völligen Mangel an weiteren Nachrichten 
nicht ausmachen, die Hauptsache war jedenfalls die, dals in Babylonien eine starke Colonie von Judäern schon seit einem Jahrzehnt bestanden hatte, als Jerusalem zerstört wurde. Was sie bis dahin zusammengehalten hatte, war freilich die Hoffnung auf Erhaltung der Stadt und ihre baldige Rückkehr dahin, aber jene Thatsache ist wichtiger als ihr Grund. Denn eben dieser Kreis war es, in dem sich die Umwandlung des alten Israel zur jüdischen Gemeinde vollzog, und was uns diesen Procefs vor allen Dingen verständlich macht, sind zwei Factoren : erstlich, dafs jene merkwürdige Wandlung sich zunächst nur in diesem kleinen Kreise vollzog, der der geistige Kern des alten Juda war und wie man aus Neh. 7 sieht, zu einem starken Bruchtheil aus Priestern bestand; zweitens der nicht minder merkwürdige Umstand, dafs dieser kleine Kreis vom heimathlichen Boden losgerissen und in ein fremdès Land verpflanzt war.

Als die Nachricht von Jerusalems Fall am Kebar eintraf, war der Widerstand der Gola gegen Ezechiel wenigstens in soweit gebrochen, als er nun öffentlich auftreten durfte. Das erste Entsetzen der Exulanten war so grofs, dal's sie die üblichen Trauergebräuche darüber vergafsen, was bei diesen Orientalen gewifs viel sagen will. Der bleibende Eindruck davon hat die ganze nachfolgende Geschichte bestimmt. Wer nicht überhaupt an der Macht Jahves verzweifeln und sich dem Heidenthum zuwenden wollte, der mufste wohl oder übel die Erklärung acceptiren, die die Propheten von dem entsetzlichen Ereignifs gaben. Ein Drittes gab es wenigstens auf die Dauer nicht. Ein überwältigendes Schuldgefühl befiel die Leute und die Bufspredigt Ezechiels sorgte dafür, dafs es nicht einschlief. Nicht weniger bestimmt wies er aber auf die Hoffnung hin, die Israel für die Zukunft hatte. Die Vorbedingung derselben war freilich die Bekehrung des Volkes. Eine solche hatte schon Hosea von einem Exil erwartet und 
namentlich hatte Jeremia dieselbe von der Wegführungs nach Babel erhofft, an den mit Jojachin Deportirten grlaubte er sic bereits zu schen. Ezechiel wiederholt seine Vorheilsung, dafs Gott das Herz des Volkes wunderbar umwandeln werde, aber er sah auch deutlich genug, wie wenig das Exil die gehofften Früchte trug. Vielmehr noch erwartete er deshalb weitere Strafgerichte, durch die Jahve alle Siinder austilgen werde. Er sah seine Aufgabe wesentlich darin, jeden Einzelnen rechtzeitig zu warnen, er wollte Seelsorger sein und als solcher die zukünftige Gemeinde sammeln. Einst als Sanherib in Juda wüthete, hatte Jesaja auf die Frage, ob Jahve denn ohne Unterschied die Glieder seines Volkes in die Hände der Assyrer fallen lasse, den Judiiern gewisse. Verhaltungsmafsregeln gegeben, deren Beobachtung die Einzelnen in der Zeit der Gefahr schützen werde (Jes. 33, 14 ff.), ähnlich machte es nun Ezechiel. Er entwickelt eine individualistische Vergeltungslehre (c. 18), freilich so einfacher Art, dals man daraus sieht, wie wenig entwickelt das Nachdenken über diese Fragen damals noch war. Das Individuum fing damals eben an, sich als eine selbständige religiöse Grölse zu betrachten. Er zählte ferner eine Reihe von Cardinalgeboten auf, deren Erfüllung oder Uebertretung die Gerechtigkeit resp. Gottlosigkeit ausmache. "Die Vergleichung dieser Gebote mit jener Definition Jesajas ist nicht nur für die beiden Propheten, sondern auch für ihre Zeiten lehrreich. Ezechiel verbietet vor allen Dingen den Höhen- und Bilderdienst, auch die levitische Reinheit taucht bei ihm auf gegenüber den sexuellen Greueln jener Zeit ${ }^{\mathbf{1}}$ ). Dann folgt eine Reihe

1) Ich begreife nicht, wie man die hierauf bezüglichen Gesetze Lev. 17 ff. für alt halten kann. Im alten Israel kamen solche Dinge schwerlich in dem Mafse vor (2 Sam. 13, 12), in dem sie diesen Gesetzgeber-beschäftigen. Im Gegentheil scheinen die dort verpönten Greuel erst spät in Israel eingedrungen zu sein und erst im Gegensatz dazu werden' sich die 'entsprechenden Ehe- und Reinigkeitsgesetze gebildet haben. 
von moralischen Vorschriften, während Jesaja lediglich solche giebt. Uebrigens dringt Ezechiel sonst wie Deuterojesaja besonders auf die Heilighaltung des Sabbaths, der im Exil das wichtigste Erkennungrszeichen des Israeliten und deshalb auch das wichtigste Band war, das die Gläubigen zusammenschlofs. Vielfach setzte die Menge freilich den Höhendienst in Babylonien fort, wer sich dazu hielt, fiel aber wohl meist zum Heidenthum ab. Ezechiel eiferte dagegen aufs heftigste, in der That widersprach es nicht nur dem Deuteronomium; sondern ebenso sehr den altisraelitischen Vorstellungen, dem Jahve im heidnischen Lande zu opfern.

Umgekehrt mufste aber aueh den Anhängern der Propheten gerade die Unterbrechung des Cultus schrecklich sein. Hieran wurde jedem Einzelnen immer aufs Neue bewufst, dafs das Band zwischen Jahve und Israel zerschnitten sei (Hos. 3, 4). Unrein war ja alle Speise, die man im heidnischen Lande genofs (Ez. 4, $9 \mathrm{ff}$ ), durch das tägliche Brod wurde Jedermann an seine Gottverlassenheit erinnert. Schon deshalb mufste der Gedanke an die künftige Wiederherstellung Israels sich namentlich auf die Wiederherstellung des Gottesdienstes richten. Es war ferner zu besorgen, dals bei längerer Dauer des Exils der Ritus in Vergessenheit gerieth, es galt ihn schriftlich zu fixiren, um ihn so auf die späteren Geschlechter zu überliefern. Ja noch mehr : ein System des israelitischen Cultus mufste überhaupt neugeschaffen werden. Selbst das gleichgültigere Detail des Gottesdienstes stand damals noch keineswegs fest. Gewifs gab es von jeher besondere Eigenthïmlichkeiten, durch die der israelitische Gottesdienst sich von anderen unterschied, aber die zahlreichen Differenzen, die sich schon aus den gelegentlichen Andeutungen der vorexilischen Literatur hierfür zwischen dem Priestercodex und der älteren Praxis ergeben, beweisen hinreichend, dafs der erstere uns keineswegs ein Bild der letzteren giebt. 
Der ilterc Cultus beruhte auf traditionellem Gebrauch, mancherlei mag sich davon durch Jahrhunderte fortgepflanzt haben, anderes wurde mit der Zeit alterirt und verdrïngt. Als geren das Ende der Königszeit das nationale Selbstbewufstsein so stark erschüttert wurde, drangen fremde Sitten massenhaft ein, gewifis auch in den Cultus. Betreffs der. Könige Ahas und Manasse ist das letztere ausdrücklich bezeugt, umgekehrt haben Hiskia und Josia nicht nur fremde Cultussitten abgestellt. Es ist freilich wahrscheinlich, dafs sich im Tempel von Jerusalem im Laufe der Jahrhunderte und namentlich aus Anläls der Reformen Hiskias und Josias eine bestimmte Tradition betr. des Cultus ausgebildet hatte, aber dafs es zur Zeit Ezechiels noch kein in allen Punkten feststehendes System gab, ist nach den wiederholten Umwälzungen der letzten Jahrhunderte wahrscheinlich und aus einzelnen Andeutungen gewifs. Ebenso verhielt es sich mit den Gebräuchen, die man unter dem Begriff der levitischen Reinheit zusammenfalst. Diese kleinen Dinge gingen zunächst natürlich nur die Priester an. Aber es handelte sich für sie dabei nicht etwa um eine wesentlich gelehrte Arbeit, sondern die Aüfgabe, den künftigen Cultus würdig einzurichten, war eine sehr ernste. Um den Götzendienst in und aufser dem Tempel hatte sich vor allen Dingen der Kampf zwischen Propheten und Volk gedreht. Der falsche, grolsentheils heidnische Cultus war Jahve fast am ärgerlichsten gewesen und darum hatte er seinen Tempel und die heilige Stadt in die Hände der Heiden fallen lassen. Darum waren auch diese kleinen Dinge schon wichtig genug. 'Ueberhaupt ist die principielle Zurückführung des gesammten Cultus auf göttliche Einsetzung nur aus dem Gegensatz gegen den altisraelitischen und heidnischen Gottesdienst zu begreifen. Wie aber mit den kleinen Dingen so stand es erst recht mit den grofsen. Es war natürlich, dafs man schon jetzt daran dachte, wie 
späterhin die so vielfach entweihte beilige Stätte wieder herzurichten sei, wie ihre Heiligkeit schou äufserlich auf den besten Ausdruck gebracht werde, wie sorgfältig sie vor jeder Entweihung zu bewahren sei. Man dachte nach über die den Priestern wohlanstehende Haltung und Tracht, über die angemessene Ordnung des Gottesdienstes, eine neue Feststellung des Kirchenjahrs. In mancher Hinsicht gab es da Fragen zu lösen, die durch die deuteronomische Reformation in Flul's gebracht waren. Es waren allerlei Folgerungen zu ziehen, die sich aus der dadurch geschaffenen Situation ergaben. Das Verhältuifs der ehemaligen Höhenpriester zu den Tempelpriesteru war endgültig zu ordnen, das Einkommen der Priester war durch die Reformation alterirt, es mufste schon auf Grund der seither gemachten Erfahrungen neu fixirt werden u. a. m.

Noch einfacher ergiebt sich dasselbe, wenn man fragt, woran sich denn überhaupt die Zukunftshoffnung knüpfte. Ezechiel entwickelt am Schlul's seines Buches eine neue Cultusordnung für das zukünftige Israel, die aber in Wahrheit eine vollständige Volksordnung ist und deshalb in der That die Krone seiner ganzen Schrift bildet, auf die das Ganze von vornherein hinausstrebt. Schon die älteren Gesetzbücher des Pentateuch gingen von dem heiligen Orte und den Sacra aus, hier dagegen dreht sich das ganze zukünftige Volksleben um den heiligen Berg. Hier erscheint wirklich wie im Priestercodex das Heiligthum als das Lebenscentrum Israels und der heilige Dienst als seine wichtigste Function. Eben durch die Vernichtung des Staates und die Wegführung des Volkes war die Bedeutung des h. Ortes aufs Höchste gesteigert. Das Volk war in alle Welt zerstreut, sein Fortbestand war nur denkbar, wenn es wieder nach Jerusalem gesammelt wurde, das war der Krystallisationspunkt, um den allein ein neues Israel sich bilden konnte, die einzige Realität, die der Glaube an Israels Zukunft in der äufseren Wirklichkeit hatte. Deshalb 
fandl die Hoffnung der Propheten jetzt den Ausdruck, dafs Jahve nach dem Zion zurückkehren und ibn nie wieder verlassen werde '). So erscheint der Berg '/ion bei Ezechiel und so crscheint er bei Deuterojesaja, nur dafs der Letztere sich in der idealen Höhe prophetischer Ideen hält, der Erstere dagegen aus den Thatsachen auch die nöthigen praktischen Consequenzen zieht. Wer Pedeutung des Tempels entsprach nothwendig die Bedeutuns des Tempeldienstes. Dazu kam der Gegrensatz gegen die Verrangenheit und die reale Lage der Gegenwart. Es war in Yukunft Israels Aufgabe Jahve festzuhalten durch angstliche Vermeidung all der Aergernisse, die man ihm früher bereitet hatte; ein reiner Gottesdienst mufste vor allem an die Stelle des abgöttischen treten. Es war nothwendiøg, dafs hierauf zunächst aller Nachdruck fiel. Im Exil entstand keineswegs das geistliche Israel, das Jahves Gesetz im Herzen trug. Einzelne Individuen der Art mochte es geben, aber eine Gemeinde, ein Volk, das dem göttlichen Willen entsprach, war zunächst nur äufserlich herzustellen. In ihrem besonderen Cultus mufste nicht nur die Gemeinde als solche in die Erscheinung treten, er mufste nicht nur das Band sein, dals sie in sich zusammenhielt und gegen die Heiden abschlofs, für die Menge mufste die Religion nach wie vor -grofsentheils im Cultus und der religiösen Sitte aufgehen, in deren Uebung wufste sie sich verschieden von den Vätern, die Jahve durch ihre Greuel gereizt hatten, hierin kam zunächst die Bekehrung zum Ausdruck. Die so zu sagen heidnische Seite der alttl. Religion tritt deshalb gerade im Judenthum äufserlich fast noch mehr heraus, als im alten Israel. Aber eben auch nur äufserlich. Denn der Cultus ist hier etwas anderes geworden, als er früher war. Er ist nicht mehr die naive Aeufserung der natürlichen Frömmigkeit und der natürlichen Gottlosigkeit, sondern sofern er in Erfüllung des göttlichen Gesetzes geübt wird, bedeutet er die Unterwerfung des Menschen unter. den Willen Gottes. Wénigstens konnte und sollte er so geübt werden. Deshalb standen der Cultus und die sittlichen Gebote Jahres nun nicht mehr wie früher einander gegenüber, sondern die physische Heiligkeit und die sittliche waren in innere Beziehung gesetzt und die erstere konnte die Basis der letzteren werden. In gewissem Sinne

1) Nebenbei bemerkt, erscheint das Schlufswort des Buches Joel 4, $21 \mathrm{mir}$ als ein starker Beweis für seine nachexilische Abfassung. 
bezeichnen Ezechiel und der Priestercodex einen Rückschritt gegen die Propheten, die so entschieden betonen, dals Jahve Gerechtigkeit und nicht Opfer verlange. Aber mit dieser einfachen Antithese kam man nicht weiter, die Nachfolger der Propheten verstanden es dagegen, die Gemeinde durch das eine zum andern zu führen. Nur so war es möglich, individuelle Frömmigkeit in weiteren Kreisen zu verbreiten.

Dafs die nachexilische Gemeinde keinen nationalen Staat bildete, hatte z. Th. gewifs darin seinen Grund, dafs die Perser nicht daran dachten, einen solchen wiederherzustellen. Aber dasselbe lag nicht weniger in der Consequenz der religiösen Entwicklung. In der messianischen Hoffnung hatte der nationale Staat sich in die Begriffe der sittlichen Weltordnung und des Weltgerichts aufgelöst, z. Th. gewifs unter dem Eindruck, den der Untergang des Staates hervorbrachte. Und die Wucht der Thatsache, dafs Israel von der Weltmacht zermalmt wurde, hat ohne Zweifel dabei mitgewirkt, dafs Israel wenigstens bis zur messianischen Zeit auf äulsere politische Grölse verzichtete. Im Inneren war aber jetzt neben dem Tempel und dem göttlichen Gesetzbuch für einen König kein Platz mehr. Es ist höchst merkwürdig, eine wie bedeutungslose Rolle der ${ }_{n}$ Fürst" Ez. 34. 40-48 spielt. Er ist nur noch ein Schatten des messianischen Königs. Er hat den öffentlichen Cultus zu bestreiten und bekommt einen Ehrenplatz im Tempel, aber nicht einmal die Gerichtsbarkeit wird ihm gelassen, die Ezechiel vielmehr auf die Priester überträgt. Vielleicht drückt er übrigens auch durch den Ausdruck Nasi die untergeordnete Rolle aus, die Israel fortan in der grofsen Politik spielen sollte. Freilich blieb die Erwartung des zukünftigen Königs populär, sofort nach dem Exil begegnet sie uns wieder. Aber welch eine Wandlung mufs die Denkweise der Juden während des Exils durchgemacht haben, wenn Sacharja dem messianischen Könige den messianischen Priester an die Seite stellt! Da sind wir nicht mehr weit von Num 27.

So waren dem Judenthum die Bahnen seiner Entwicklung vorgezeichnet und zwei mächtige Triebfedern waren es, die dieselbe zu einer stetigen machten, nämlich die Erinnerung an den entsetzlichen Untergang des alten Reichs und andererseits die messianische Hoffnung. Die herrliche Endzeit, von der die Propheten geweissagt hatten, trat nicht ein, als jenes grofse Heer von Juden unter Josua und Serubbabel aus dem Exil zurückwanderte, aber nie ist die 
jullische Oemeinde an der Ilofinung irre geworden, dafs sio einst kommen werde. Dafu we noch nicht da war, In machte einmal Jahves Worn uber die Bunden der Vater, der immor noch kein Ende hatte, der Zorn, desnen bleiernen Druck da Judenthum weitdem nie wieder losgeworden ist und dem gegenuber man in dem Bewulstsein der eigenen Stundo hin und wieder vorzweifeln zu munnen schien. Jann war aber such die Nichterfullung der Weissagung daraus xu begreifen, dafo das Gesetz noch immer nicht erfullt war und die Gemeinde den gottlichen Anforderungen nicht entsprach. Bis dahin war es ein weiter Weg. Schon Ezechiel hat davon ein Bewufstsein, sofern seine Gesetzgebung deutlich die 'T'endenz hat, ftr die Zukunft dem Ruckfall in die alten sunden praktisch vorzubeugen.

Fur uns ist es nanentlich wichtig zu. sehen, wie langsam sich die Constituirung der judischen Gemeinde vollzog, ein ganzes Jahrhundert ging daruber hin. Die Zahl der mit Jostas und Serubbabel Zurlickgekehrten (ca. 42000 Miinner) erscheint sehr grofs im Vergleich zu den von Nebukadnezar nach Babel Deportirten (ca. 15(00)). Da obendrein eine grofe Zahl von Juden in Babylonien zuruckblicb, so muls man annehmen, dafs aufser den Deportirten noch eine grofse Zahl von eigentlichen Kriegsgefangenen nach Babel abgefuhrt war, die dort inzwischen aut die eine odor andere Art frei geworden waren. Auffallend klein orscheint dagegen die Zahl der Zurückgekehrten im Vergleich zu dor grofsen judischen Bevolkerung, die wir spïter in Paliistina finden. So viel ich weirs, hat zuerst $\mathrm{K} u$ enen die richtige Erklïrung hiervon gegeben. Die netue Colonio wurde nicht nur durch weitere Nachzüge aus Babylonien verstïrkt, vielnehr hat sie allmählich einen grofsen Theil der israelitischen Berölkerung aufgesogen, dio während des Exils im Lande geblieben war; vgl. Neh. 10, 29. Esr. 6, 21. Zunächst kam es freilich nicht dahin. Im Gegentheil war die Constituirung der judischen Gemeindo wesentlich dadurch bedingt, dals die Gola sich von diesen ihren Brüdern abschlofs. Die letzteren hatten nämlich wiihrend-des Exils das alte Wesen weiter getrieben, sio waren wo moglich noch heidnischer geworden und hatten sich z. Th. sogar mit Heiden vermischt. Einfach Heiden waren sie freilich keineswegs, es ist cum grano salis zu verstehen, wenn Nehemia seine Gegner als Ammoniter und Araber bezeichnet. Dafs sie im Gegentheil Israuliten waren, zeigt sowohl ihr Name (Tobia) wie ihr Anspruch (Neh. 2, 20. 13, 4 ff.). Auch ist es ein Ana- 
chronismus, wenn der Chronist(Esr. 4,1) sie mit den Samaritern identificirt, da die samaritanische Gemeinde sich vielmehr erst in Folge dieser Kämpfe bildete. Es war natürlich, dals die neue Colonie von einer Gemeinschaft mit diesen nichts wissen wollte, wenigstens mulsten die Trägrer des neuen Geistes sich dem aufs Entschiedenste widersetzen, wenn sie nicht alle Früchte des Exils preisgeben wollten. Es scheint in der That, dafs die im Lande Zurückgeblicbenen sofort nach der Rückkehr der Gola sich an die neue Gemeinde anzuschliefsen versuchten, dabei aber abgewiesen wurden. Der nicht sehr zuverlässigen Erzählung Esr. 5 liegt gewifs soviel 'Thatsächliches zu Grunde, auch betrachtete man anfangs die strenge Absonderung der Gola, des heiligen Samens, als selbstverständlich (Esr. 9).

Die mit Josua und Serubbabel Heimgekehrten waren im Allgemeinen gewil's solche, die für die Ideen eines Ezechiel gewonnen waren. Fast der zehnte Mann war ein Priester und die grolse Rolle, welche der Priester Josua in der neuen Gemeinde spielte, ist aus dem Buche Sacharja deutlich. Aber die Schwierigkeit der Ansiedlung in dem verwüsteten Lande, mehrfacher Milswachs, überhaupt die ärmliche Lage der Colonie lief's die anfängliche Begeisterung der Menge bald in grofse Entmuthigung umschlagen. Wohl kaum ist in der Geschichte auf grofse Erwartungen eine so grolse Enttäuschung gefolgt. Fast zwei Jahrzehnte gingen darïber hin, ehe der Tempelbau in Angriff genommen wurde. Noch einmal bewährte da das prophetische Wort seine Kraft, Haggai und Sacharja setzten den Tempelbau durch, und noch einmal lebte die messianische Weissagung auf. Im Gegensatz gegen den elenden Zustand und die Muthlosigkeit der Gemeinde knüpften diese Propheten an die Vollendung des Tempels die grölsten Hoffnungen, die zugleich durch grolse politische Bewegungen in Vorderasien angeregt waren. Sie meinten schon auf die Träger des messianischen Reiches hinweisen zu können (vgl. noch Neh. 6, 7). Gerade darin zeigt sich freilich wohl am deutlichsten, dals es mit der Prophetie zu Ende ging, wenn man überhaupt diese Männer noch als eigentliche Propheten gelten lassen will. In Wahrheit mul's schon Jeremia für den letzten Propheten gelten. Die Zeit erforderte jetzt andere Männer. Haggai und Sacharja hatten wohl für den Augenblick die Menge mit sich fortreil'sen können, aber auf die Dauer erfolgte nothwendig ein um so gröfserer Rückschlag. Von neuem rils dieselbe Gleichgültigkeit und Mattherzigkeit ein. Als sechzig Jahre 
spiiter Esra nach Jerusalem kam, hatte die Colonie sich vielfach den Briddern da draufsen genähert, namentlich war das seitens der vornehmeren Gemeindeglieder, der Priesterschaft unil des Adels reschehen. Zwischenheirathen kamen in grofser Zahl vor. Die Gefahr, dals die beiden Theile sich mit einander vermischten, war grofs und es stand alles auf dem Spiel, was in den letzten .Jahrhunderten erreicht war. Eben in dieser Situation wurden Esra und Nehemia die eigentlichen Begründer der jüdischen Gemeinde, der eine, indem er der Gemeinde das Gesetzbuch gab, der andere, indem er die ïufseren Bedingungen schuf, unter denen allein die Herrschaft des Gesetzbuchs möglich war.

In Babylonien war ein grofser Theil der Exulanten zurückgeblieben, manche aus Gleichgültigkeit; manche aber auch aus anderen Gründen. Wir gewinnen sogar den Eindruck, dafs dort die Ideen Ezechiels viel lebendiger fortlebten, als in Palästina. Von dort kam das Gesetzbuch, von dort kamen Esra und Nehemia. Die Religion war inzwischen so consolidirt, dafs selbst fern vom heiligen Lande jüdische Frömmigkeit und jüdische Gemeinden möglich waren. Es ist auch ganz begreiflich, dafs man mitten unter den Heiden und fern von den trübseligen Zuständen der heiligen Stadt mit viel gröfserem Eifer für die Sache des Glaubens lebte und arbeitete, als in Jerusalem, -wo man in steter Berührung mit ganz anders gearteten Israeliten und im Kampfe mit den realen Aufgaben der Wirklichkeit eher matt wurde. Wie oft ist nicht seitdem die Diaspora die zweite Mutter der Kirche geworden!

Esrà führte einen grofsen Zug von Juden nach Juda zurück. Er ahnte nicht, wie schlimm es dort stand, aber gewifs hatte er eine ungefähré Vorstellung von den dortigen Verhältnissen. Er wollte der Gemeinde frisches Blut zuführen, vor allen Dingen beabsichtigte er die Einführung des Gesetzbuchs durchzusetzen. Man hatte freilich das Deuteronomium. Nach Josias Tode war es nicht abgeschafft; es blieb bei den. Anhängern der Propheten im höchsten Ansehen und machte sich sogar im öffentlichen Leben gelegentlich geltend (Jer. 34). . Die gesammte Literatur des A. T., die aus dem Exil und dem ersten Jahrhüdert nach dem Exil stammt, ist aufs stärkste vom Deuteronomium beeinflufst, namentlich der Prophet Ezechiel und die sog. deuteronomistische Redaction des Pentateuchs und der historischen Bücher. Auch in der neuen Gemeinde 
stand es in hohen Ehren, wie namentlich aus Esra 9. 10 hervorgeht. Aber die damalige Lage der Dinge war unhaltbar. Was der Gemeinde vor allen Dingen Noth that, war die thatsächliche Herrschaft des Gesetzes über alle. Die messianische Zeit war noch weit, darüber konnte man sich keinen Illusionen mehr hingeben, überhaupt aber war ihr Kommen doch nur denkbar, wenn die ganze Gemeinde einmüthig in der Erfüllung des Gesetzes thätig war. Und nur wenn ein Bewufstsein hiervon die Einzelnen beseelte, war für die Zukunft Besserung zu hoffen. Jedenfalls bedurfte es deshalb einer ausdrücklichen Anerkennung des Gesetzes von Seiten der ganzen Gemeinde, da jener Bundesschlul's unter Josia für sie doch keine unmittelbare Bedeutung mehr hatte. Materiell reichte ferner das Deuteronomium längst nicht mehr aus. Das beweisen schon die anderen gesetzlichen Schriften, die inzwischen entstanden waren. Seit Josia hatte sich allzuviel geändert. Freilich nach ihrer privatrechtlichen Seite genügten die alten Gesetzbücher mehr oder weniger, aber nicht nach der gottesdienstlichen, die unterdessen eine ganz andere Bedeutung gewonnen hatte. Eine Hauptsache war in letzterer Hinsicht schon die Fixirung der Abgaben und des Einkommens der Priester und hierfür genügte z. B. auch die Schrift Ezechiels nicht, der hierin natürlich die praktischen $\mathrm{Be}$ dürfnisse der jüdischen Gemeinde nicht hatte vorausberechnen können. Bei dem Ernst, mit dem man jetzt alles Derartige auffalste, wollten aber alle solche Dinge gesetzlich fixirt sein. Auch müssen wir annehmen, dals manche Seiten des Cultus- und Ceremonialgesetzes in dem Jahrhundert, das seit Ezechiel verflossen war, noch weiter ausgebildet waren. So entstand das Gesetzbuch Esras. In Wahrheit war es das Werk einer ganzen Schule von Schriftgelehrten, aber sein einheitlicher Grundgedanke ist derselbe, der uns zuerst bei Ezechiel begegnet, der hier aber consequent nach allen Seiten entwickelt ist.

Anfangs erzielte Esra durch sein entschiedenes Auftreten und den Eindruck, den sein Eifer auf die Gemeinde machte, einen grofsen Erfolg. Zunächst erstrebte er die strenge Absonderung der Gemeinde von ihren halbheidnischen Brüdern und wirklich setzte er die Scheidung aller gemischten Ehen durch. Aber nicht lange darauf erlitt er eine um so empfindlichere Niederlage. Der betreffende Passus seiner Memoireu ist freilich von einem der späteren Bearbeiter unterdrückt, zwischen dem Buche Esra und 
Nehemin klafft eine Lilcke von 12 Jahren $\left.{ }^{1}\right)$. Indessen konnen wir aus dem Buche Nehernia das Fehlende in der Hauptsache ergiinzen. Die Feinde, welche die Mauern von Jerusalem zerstört, die Thore verbrannt und iberhaupt Ungliick und Schmach uber die Gemeinde gebracht hatten, sind ohne $\%$ weifel dieselben, welche nachher die Wiederherstellung der Mauern anf alle Weise zu hintertreiben suchten, d. h. Sanballat, Tobia und Gesem, die dabei vielleicht gar einen Auftrag der persischen Regierung vollstreckt hatten. Gewil's wollten diese Miinner mit Gewalt ihr Anrecht an dem Tempel geltend machen and ihre Aufnahme in die Gemeinde erzwingen, nachdem Esra durch Auflösung der Mischehen ihre Ansschliefsung von Neuem durchgesetzt hatte. Und wie später die vornehme Priesterschaft und die Aristokratie, die namentlich mit dem Tobia theils verschwägert theils verbündet war (Neh. 6. 13), dem Nehemia gegenüber mindestens eine zweideutige Haltung einnahm, so darf man auch wohl annehmen, dafs sie schon vorher mit jenen Häuptlingen gegen Esra gemeinsame Sache gemacht hatte. In der That bestand zwischen ihnen eine Solidarität dęr Interessen. Durch die von Esra angestrebte Einführung des Gesetzes war die Herrschaft der mächtigen und reichen Aristokratie bedroht. Nehemia

- stützte sich ihnen gegenüber auf die kleinen Leute, für die er einen Schuldenerlafs vom Adel erzwang (Neh. 5). Es ist wohl auch nicht zufällig, worauf schon $\widehat{D}$ uhm aufmerksam gemacht hat, dal's die trübseligen Reste der Prophetie mit den Gegnern Nehemias conspirirten. Nehemias Memoiren sind uns freilich nicht vollständig erhalten, aber schwerlich sind sie bedeutend verkürzt, er erzählt fast nur von der Wiederherstellung der Mauern von Jerusalem, die er doch in wenigen Wochen bewerkstelligte. In Wahrheit war das eine That, die für die definitive Constituirung der jüdischen Gemeinde von grundlegender Bedeutung war. Denn unter dem Schutz, den diese Mauer gegen die halbheidnischen Brüder da draufsen bot, und unter dem $\mathrm{Zwang}$, in dem sie die widerstrebenden Elemente im Innern der Stadt hielt, haben Esra und Nehemia die Herrschaft des Gesetzes aufgerichtet und dauernd gesichert.

1) Aller Wahrscheinlichkeit nach gehört in dieso Lücko die aramüische Erzilhlung von Esra 4, wie u. a. Bertheau gesehen hat. Auffallond ist nur, dals dort ganz andere Namon genannt worden als im Buche Nehemia. 
Wir sind über die Geschichte der nachexilischen Gemeinde im Allgemeinen sehr unvollkommen unterrichtet, aber dafür haben wir in den Memoiren Esras und Nehemias historische Documente ersten Ranges, die auf die Bedingungen, unter denen die jüdische Gemeinde endlich zu Stande kam, helles Licht werfen. Die Persönlichkeiten des Schriftgelehrten und des Laien treten uns in lebendigster Anschaulichkeit vor Augen, sie sind der genuine Ausdruck der damaligen jüdischen Frömmigkeit, die uns hier in voller Originalität und Lebenswahrheit entgegentritt. Auch die Gegensätze, in denen sich später das innere Leben der jüdischen Gemeinde bewegte, liegen ihren Keimen nach schon hier vor und das kann uns einigermalsen darüber trösten, dals wir über die nächsten Jahrhunderte so gut wie nichts wissen. Von allgemeinerem religionsgeschichtlichen Interesse ist übrigens der Umstand, dafs die Constituirung der jüdischen Gemeinde zuletzt nur unter dem Beistande der heidnischen Weltmacht gelang.

\section{Deuterozacharja.}

Eine kritische Studie.

Vom Heransgeber.

II. Theil. Die aus der innerjüdischen Geschichte zu entnehmenden Gründe.

(siehe Jahrgang 1881, S. 1 ff.)

Dals ${ }^{1)}$ Za. 9-14 ein nachexilisches Schriftstück ist, ist Jahrgang 1881, S. 1 ff., erwiesen worden. Aus den

1) Ich bedaure, bei Aufzählung derjenigen Gelehrten, welche der auf oberflächlicher Untersuchung des Inhalts erwachsenen und gcdankenlos weiter nachgesprochenen kritischen Ansicht über Za. $9 \mathrm{ff}$. auf Grund eigenen Nachdenkens widersprochen haben, F. Böttcher 